Volume (4) No. (2) 2021

استخدام شبكات التواصل الاجتماعي في تفعيل التواصل الأمثل بين الكلية وطلابها "فيسبوك نموذجاً"

عبدالسلام عبدالحميد عمران \& إياد علي مفتاح بالحاج 


\section{استخدام شبكات التواصل الاجتماعي في تفعيل التواصل الأمثل بين الكلية وطلابها "فيسبوك نموذجاً" عبدالسلام عبدالحميد عمران}

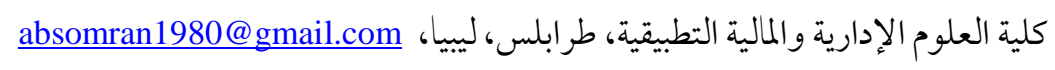

$$
\text { إياد علي مفتاح بالحاج }
$$

كلية العلوم الإدارية والمالية التطبيقية، طر ابلس، ليبيا، eyadbelhaj7@gmail.com

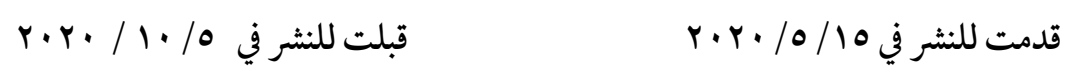

الملخص: هدفت الدراسة إلم التعرف علئ مستوى استخدام شبكة التواصل الاجتماعي فيسبوك في تفعيل التواصل الأمثل بين الكلية وطلابها، وذلك من خلال قياس مستويات الـنشر، الاستجابة، والخصوصية. إلى جانب الكشف عما إذا كانت هناك فروق ذات دلالة إحصائية بين استجابات أفراد عينة الدراسة تعزئ لمتغيرات الجنس، والتخصص. استخدمت الدراسة المنهج الوصفي التحليلي، وتم جمع البيانات بو اسطة استبانة معدة خصيصاً لأغر اض الدراسة ومكونة من (7) (1 ) فقرة، ثم تم توزيعها علن عينة الدراسة المكونة من (rYM) طالباً وطالبة من الكلية. وبعد إجراء التحليلات الإحصائية اللازمة توصلت الدراسة إلى أن مستوئ استخدام شبكة التو اصل الاجتماعي في تفعيل التو اصل الأمثل

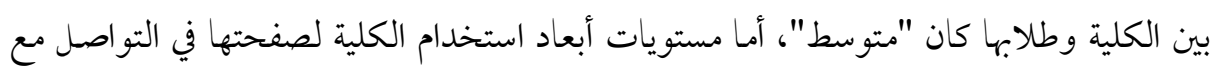

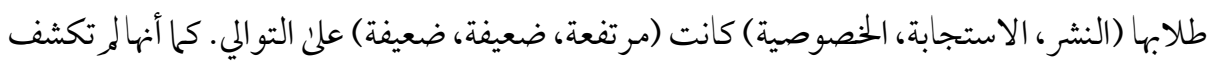
عن فروق ذات دلالة إحصائية عند مستوى (0 • , · = م) بين استجابات أفراد عينة الدراسة على استبانة التواصل تبعاً لمتغيري الدراسة (الجنس، التخصص). وانتهت الدراسة بتقديم تصور مقترح لاستخدام شبكة التو اصل الاجتماعي فيسبوك في تفعيل التو اصل الأمثل بين الكلية وطلابها. الكلمات المفتاحية: شبكات التو اصل الاجتماعي، التو اصل، النشر، الاستجابة، الخصوصية. 


\title{
The Use of Social Networks to Activate the Optimal Communication between the College and its Students "Facebook Model"
}

\author{
Abdulsalam A. Omran \\ College of applied administrative and financial sciences, Tripoli, Libya, \\ absomran1980@gmail.com \\ Eyad A. Belhaj \\ College of applied administrative and financial sciences, Tripoli, Libya, \\ eyadbelhaj7@gmail.com
}

Presented in 15th may 2020

Accepted in 5th October 2020

\begin{abstract}
The study aimed to identify the degree of use of social networking, Facebook in the activation of optimal communication between the college and its students, by measuring the degrees of publishing, response and privacy, In addition to reveal whether there are statistically significant differences between the responses of the sample used in the study attributed to the variables of the study i.e. sex, specialization, in order to reach a proposed concept. The study used the descriptive analytical method to achieve its objectives. the data were collected by means of a questionnaire prepared specifically for the purposes of the study and consisted of (16) paragraphs, which was verified for its validity and reliability, then it was distributed to the sample of the study which consists of (322) students' male and female from the College. After conducting the necessary statistical analyzes, the study found that the degree of using the social network to activate the optimal communication between the college and its students was "medium", the scores of the college's use of its page in communicating with its students (publishing, response, privacy) were (high, weak, weak) respectively. It also did not reveal statistically significant differences at ( $\alpha=$ 0.05 ) between the responses of the study sample on the communication questionnaire according to the study variables i.e. sex, specialization. The study ended with a proposal to use the social network, Facebook to activate the optimal communication between the college and its students.
\end{abstract}

Key Words: Social Networks, Communication, Publishing, Response, Privacy. 
الإنسان كائن اجتماعي بطبعه، حيث جُبِلَ علن التواصل منذ بدء الخليقة، فاللغة هي أداة

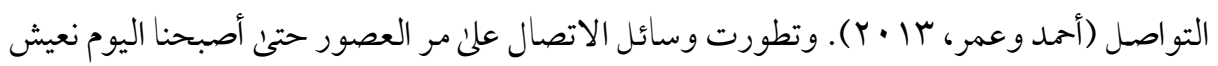

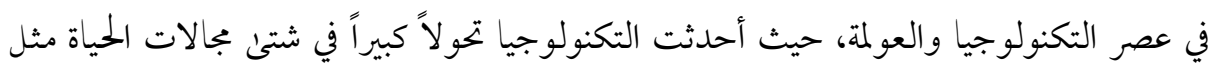
التعليم والطب والصناعة والعلوم وكذلك الحال في مجال التو اصل الاجتماعي بين البشر. إذ أسهمت هذه التكنولوجيا في التطور الهائل في عالمر الاتصالات، وبظهور الإنترنت الذي ربط كافة أرجاء المعمورة ببعضها البعض الأمر الذي جعل العالريشبه القرية الصغيرة. فقديهاً كان التو اصل يتم عن طريق الرؤية

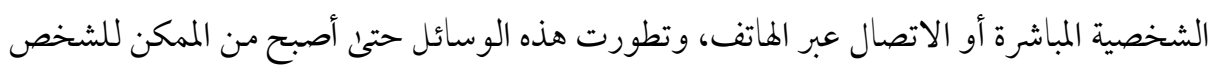
التواصل مع غيره في أي مكان وأي زمان. وبإمكانه الإرسال والاستقبال والتفاعل والتعقيب والاستفسار والتعليق بمنتهن الحرية وبسرعةٍ عالية، بالإضافة للتو اصل بصفةٍِ مباشرة وفورية، وتبادل

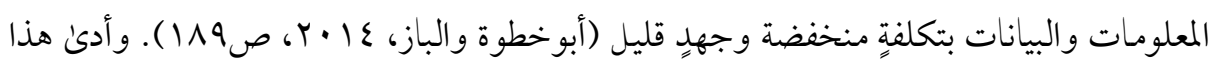

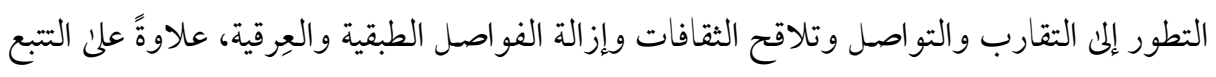
السريع للأحداث التي تجري في الساحة المحلية والعالمية، هذا النمط من التفاعل الاجتماعي الذي تسلت إليه التكنولو جيا سمي بشبكات التواصل الاجتماعي (Social networks). هذه الشبكات التي فرضت نفسها بقوة بين جميع شرائح المجتمع، يعد موقع "فيسبوك" من أهمها وأكثرها استخداماً في كل أنحاء العالر لدى جميع الفئات السنية بشكلٍ عام ولدئ شريحة الشباب بشكلٍ خاص (الفتحي وآخرون،

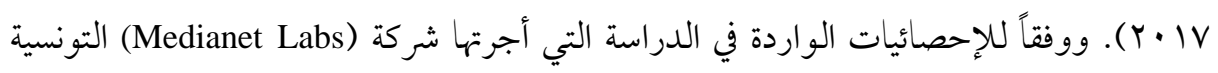
المتخصصة في هندسة الكمبيوتر وخدمات الإنترنت عام (Y V · r)؛ والتي جاء فيها أن ليبيا تحتل المركز الرابع في قارة أفريقيا من حيث نسبة مستخدمي فيسبوك من إجمالي عدد السكان، حيث بلغت نسبة من

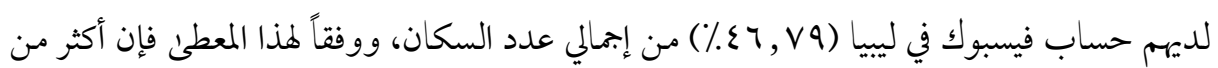

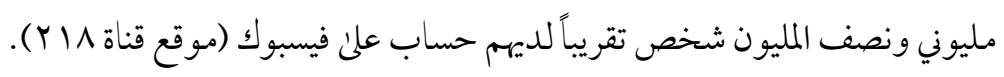


وفي ظل هذا التقدم السريع في ججال التو اصل و إقبال طلبة التعليم الجامعي على مواقع شبكات التواصل الاجتماعي، أصبحت الجمامعات تتعامل مع جيل من الطلبة الرقميين يتعاملون مع هذه

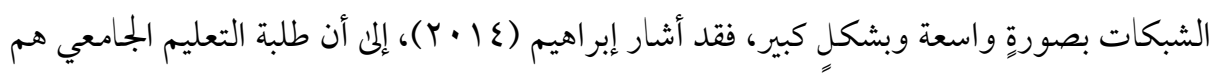
الأغلبية في استخدام مواقع التواصل الاجتماعي المختلفة. وقد لفت هذا الانتشار الشاسع لهذه الشبكات أنظار القائمين علن المؤسسات التعليمية في جميع الدول، فهي تعتبر بيئة مناسبة لتعليم مختلف ومتقدم عن التعليم التقليدي، لتنطلق إلى تعليم منفتح

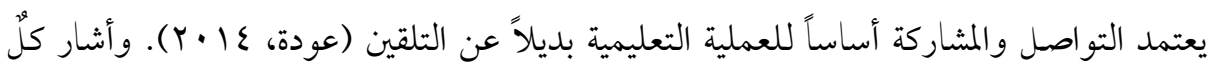
من(Towner and Munoz, 2009) إلى أن زيادة درجة استخدام فيسبوك في العملية التعليمية يرجع للمزايا التي يقدمها للطالب والمعلم، الأمر الذي جعل الأنشطة التعليمية أكثر كفاءة وفاعلية، ومنها توفير خاصية الإعلانات وخدمات الرسائل، بالإضافة إلى إتاحة تحميل الملفات و الصور و الفيديوهات

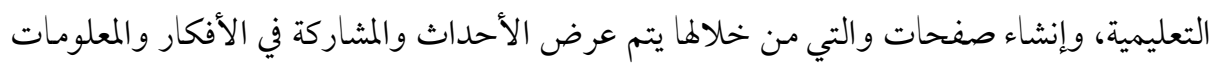
وإضافة التعليقات بكل حرية.

\section{مشكلة الدراسة وتساؤلاتها:}

تسعى المؤسسات التعليمية سعياً حثيثاً لتجويد الخدمات التعليمية التي تقدمها مستخدمةً في ذلك كل الوسائل الحديثة التي من شأنها الارتقاء بالتعليم ومواكبة التطور في الوسائل التعليمية. وبظهور شبكة التو اصل الاجتاعي فيسبوك واستخدامها في اغر اضٍ شتى من ضمنها التعليم، بالإضافة إلى قيام أغلب مؤسسات التعليم العلي بإنشاء صفحات علن شبكة التو اصل الاجتماعي فيسبوك بغية

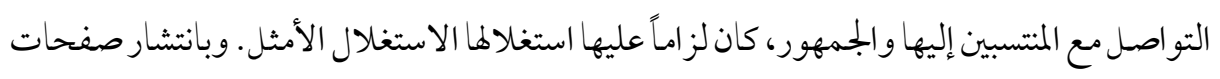
الجامعات والكليات علن شبكة التو اصل الاجتماعي فيسبوك يبقى الاستعمال سيد الموقف، فهل تقوم بتوظيف صفحاتها بطريقة فعالة تحدم طلابها المستفيدين منها بالدرجة الأولن؟ من هنا يمكن تلخيص المشكلة في السؤال الرئيسي الاتي: ما مستون استخدام شبكة التواصل الاجتماعي فيسبوك في تفعيل التو اصل الأمثل بين الكلية وطلابها؟ 
وينبثق عن هذا السؤال الرئيسي الأسئلة الفرعية الأتية:

س ا ـ ما مستوى توظيف الكلية لصفحتها علئ شبكة التو اصل الاجتماعي فيسبوك في النشر عن انشطتها المختلفة من وجهة نظر الطلبة؟ س r. ما مستون استجابة صفحة الكلية علن شبكة التواصل الاجتماعي فيسبوك للرسائل والاستفسار ات التي يقدمها لها الطلبة من وجهة نظر الطلبة أنفسهم؟ س r. ما مستوئ المحافظة علن الخصوصية عندما تتو اصل الكلية مع طلابها عبر صفحتها علن شبكة التو اصل الاجتهاعي فيسبوك من وجهة نظر الطلبة؟

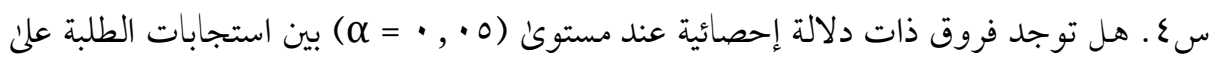

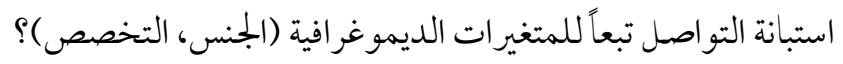

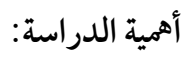

تأتي أهمية هذه الدراسة من الأهمية التي حققها الانتشار الواسع لصفحات الكليات على شبكة التو اصل الاجتماعي فيسبوك، مما يجعل هاوسيلةً متطورة وفعالة في احداث التو اصلل إذا تم استخدامها بفاعلية، بعيداً عن الأساليب التقليدية، كما يستمد البحث أهميته من العديد من العبارات يمكن ايجازها

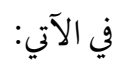

أ- تتجسد أهمية الدراسة بالنسبة للكلية قيد البحث سعياً لتحسين مستوى أداءها والخدمات التي تقدمها، فاستخدام صفحة الكلية بطريقةٍ فعالة في التواصل مع محيطها بشكلٍ عام

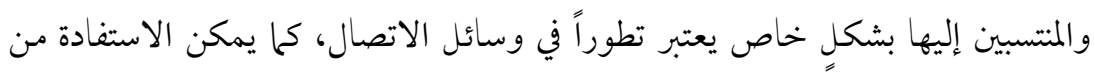
التصور المقترح لهذا البحث من الناحية التطبيقية بالنسبة للكليات الاخرىن. ب- تستمد أهمية الدراسة في أنها تستهدف طلبة الكلية وهم المتأثرون بالمشكلة بشكلٍ مباشر و أكثر من غيرهم من العاملين والجمهور، لاسيا وأنهم يسعون للتو اصل مع الكلية بشكلٍ مستمر. 
تستمد الدراسة أهميتها من قلة البحوث والدراسات التي تناولت موضوعها، وأنه على حد علم الباحث لا تو جد دراسة ليبية أو عربية تناولت استخدام شبكات التو اصل الاجتماعي في تفعيل التو اصل بين الكلية والطلبة. د- قد يستفيد أعضاء هيئة التدريس من نتائج هذه الدراسة، إذ يمكن أن تشكل لهم نقطة انطلاق لتوظيف شبكة التو اصل الاجتهاعي فيسبوك واستخدام المجموعات المغلقة للطلبة، التي ينتج من خلالها الاتصال النقاش والحوار حول المادة الدراسية، بعيداً عن التلقين. ه- إسهام هذا البحث في تبصير المسؤولين عن إدارة الكلية باستخدام مو اقع التو اصل الاجتماعي المختلفة، ودورها الفعال في احداث التطوير أو في تفعيل التو اصل بين الكلية والطلبة. و- يتوقع أن تفيد هذه الدراسة المجتمع الذي يرغب في التو اصل مع المؤسسات التعليمية. ز- قد تُكَون هذه الدراسة قاعدة معلوماتية ونقطة مهمة لإجراء دراسات وأبحاث أخرىن

$$
\text { مستقبلية أخرى تجرى في نفس المجال. }
$$

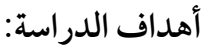

في ضوء مشكلة الدراسة، فإن البحث يسمو لتحقيق الهدف الرئيسي؛ وهو التعرف علن مستوى استخدام شبكة التو اصل الاجتهاعي فيسبوك في تفعيل التو اصل الأمثل بين الكلية وطلابها، ويتفرع منه

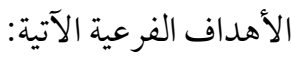

أ- تحديد مستوكن توظيف الكلية لصفحتها علن شبكة التو اصل الاجتماعي فيسبوك في النشر عن أنشطتها المختلفة من وجهة نظر الطلبة.

ب- تحديد مستون استجابة صفحة الكلية على شبكة التواصل الاجتماعي فيسبوك للرسائل والاستفسارات التي يقدمها لها الطلبة من وجهة نظر الطلبة أنفسهم. تحديد مستوى الخصوصية عندما تتو اصل الكلية مع طلابها عبر صفحتها على شبكة التو اصل ج الاجتماعي فيسبوك من وجهة نظر الطلبة. 


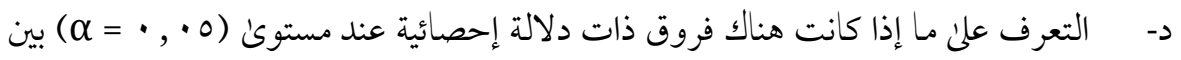
استجابات الطلبة على استبانة التواصل تبعأللمتغيرات الديموغرافية (الجنس، التخصص).

\section{مصطلحات الدراسة: - n}

يقصد بالتعريف الإجرائي تحديد المصطلح بإبراز دلالته الاستعالية في البحث، وفيما يلي نستعرض مصطلحات الدراسة والتعريف الإجرائي لكل مصطلح:

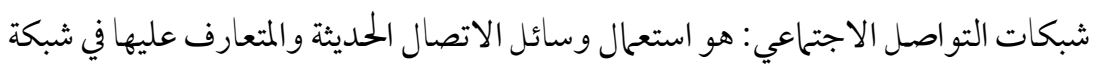

الاتصالات العنكبوتية (الإنترنت) كوسيلة للتو اصل، كان ذلك سمعياً بصرياً أو كتابياً. فيسبوك: هو أحد مواقع التواصل الاجتماعي المستخدم في شبكة الاتصالات العنكبوتية (الإنترنت)، والذي يمكن مستخدميه من التواصل فيما بينهم، ونشر أخبارهم وتبادل وجهات نظرهم في القضايا والأفكار التي يطرحونها.

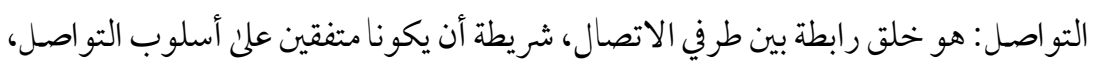
وذلك باستخدام وسائل الاتصال المتعارف عليها في شبكة الاتصالات العنكبوتية

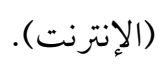

الكلية: هي المؤسسة التعليمية التي ينتسب إليها الطلبة، وهي تمثل الطرف الأول في الاتصال. الطلبة: هم الدارسين بالكلية وينتمون إليها، وهم يمثلون الطرف الثاني في الاتصال.

حدود الدراسة: na na

تخضع الدراسة إلى الحمدود الأتية: أ- الحدود الموضوعية: اقتصرت الدراسة علن استقصاء اراء طلبة كلية العلوم الإدارية والمالية التطبيقية حول استخدام شبكات التواصل الاجتماعي في تفعيل التو اصل الأمثل بينهم وبين

الكلية.

ب- الحدود المكانية: طبقت الدراسة علن كلية العلوم الإدارية والمالية التطبيقية والكائنة بالعاصمة طر ابلس. 
ج- الحدود الزمنية: تم تنفيذ الجزء الميداني من الدراسة في الفصل الدراسي ربيع (19 • (Y).

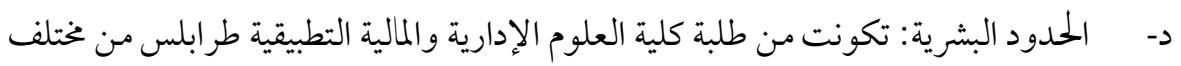
التخصصات والفصول الدراسية.

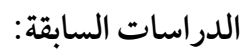

هناك العديد من الدراسات السابقة التي تناولت شبكات التواصل الاجتماعي، إلا أن الباحث قام بمراجعة ما توفر لديه من الأدب التربوي واختيار الدراسات التي ترتبط بشكل جزئي مع هذه الدراسة، حيث تم ترتيب الدراسات حسب تسلسلها الزمني من الأحدث إلى الأقدم، وفيما يلي نستعرض بإيجاز هذه الدراسات.

- دراسة الشديفات والزبون بعنوان "واقع توظيف مواقع التواصل الاجتماعي في العملية

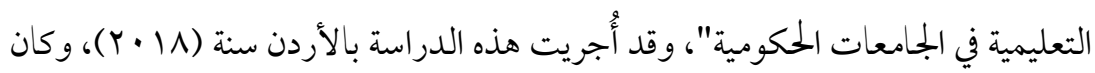
من أهم أهدافها التعرف علن درجة توظيف مو اقع التواصل الاجتماعي في العملية التعليمية في الجامعات الأردنية الحكومية من وجهة نظر الطلبة. وقد توصلت الدراسة إلى أنه هناك درجة توظيف منخفضة لمواقع التواصل الاجتحاعي في العملية التعليمية في المجال المعرفي و التقويمي والمهاري. - دراسة حنتوش بعنوان "مواقع التواصل الاجتماعي ودورها في قطاع التعليم الجامعي كلية

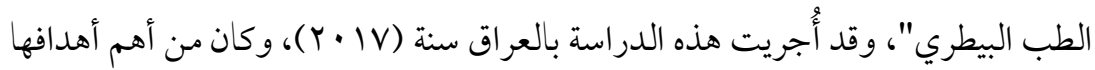
التعرف علن آثار التصور الذهني الجديد بأن لمواقع التواصل الاجتماعي أثراً فاعلاً في ميدان التعليم، مقارنة بالإقبال المتز ايد لمستعملي هذا الموقع من قبل الأستاذ والطلبة، وما يمكن أن تقدمه هذه المواقع من تحسين واقع التعليم الجامعي، وإمكانية توظيف مواقع التواصل الاجتماعي في التعليم. وقد توصلت الدراسة إلى أن مواقع التو اصل الاجتماعي لها فوائد عدة يمكن توظيفها في التعليم الجامعي، وأن لهذه المواقع تأثيراً كبيراً في التواصل الأكاديمي بين الطلبة. 
- دراسة عواج وسامية بعنوان "دور مواقع التو اصل الاجتماعي في دعم التعليم عن بعد لدئ الطلبة الجامعي"، وقد أجريت هذه الدراسة بالجزائر سنة (Y ( ) )، وكان من أهم أهدافها الكشف عن مدئ مساهمة مو اقع التواصل الاجتماعي في تحقيق أهداف التعلم عن بعد، وما

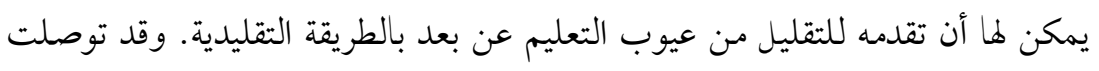

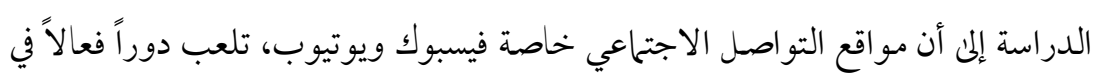
عملية التعليم عن بعد، وتساهم بشكل كبير في تذليل عيوب التعليم التقليدي. - دراسة اليحيا بعنوان "استخدام مواقع التو اصل الاجتماعي في التعليم العالي"، وقد أُجريت

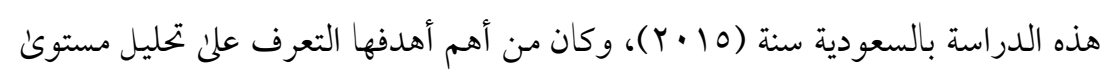

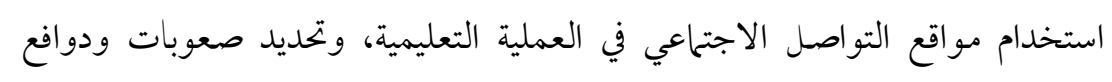

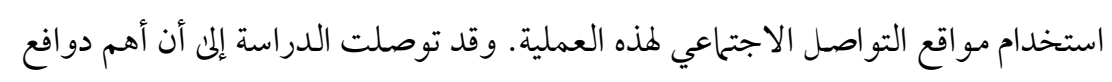
استخدام مواقع التواصل الاجتماعي في العملية التعليمية هي القدرة على مشاركة وتبادل

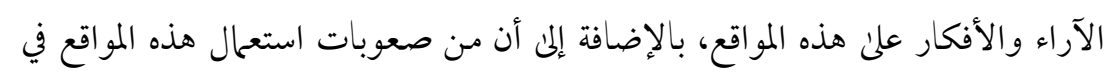

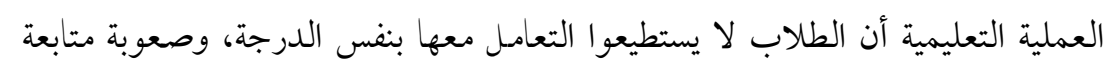

الأنشطة التعليمية عليها. - - دراسة المشيقح بعنوان "أثر شبكات التواصل الاجتماعي في التعليم"، وقد أُجريت هذه

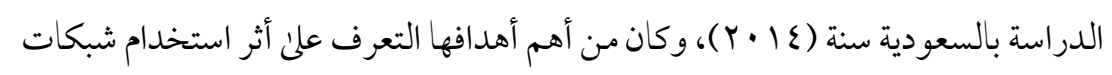

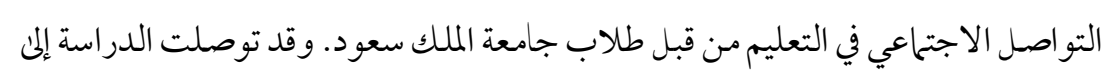
أن الإيجابية نحو أهمية استخدام شبكات التو اصل الاجتماعي (فيسبوك) في التعليم، وتسهيل

\section{وتعزيز العملية التعليمية.}

- دراسة إبراهيم بعنو ان "واقع استخدامات شبكات التو اصل الاجتماعي في العملية التعليمية

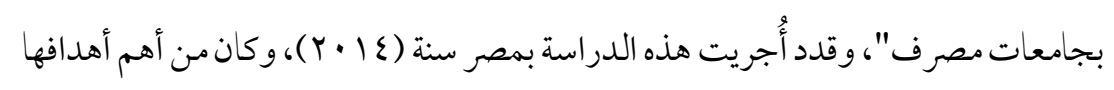
التعرف على واقع استخدام شبكات التواصل الاجتماعي في العملية التعليمية لدى أعضاء 
هيئة التدريس و الطلاب بجامعات صعيد مصر (الوادي - أسيوط - سوهاج) . وقد توصلت الدراسة إلى أن استعمال شبكات التو اصل الاجتماعي في العملية التعليمية بالتعاون مع أعضاء هيئة التدريس بدرجة متوسطة، وأحياناً تكون ضعيفة، بالإضافة إلى وجود معوقات بدر جلي كبيرة مثل انعدام القوانين التي تضمن الخصوصية، وسلبية أعضاء هيئة التدريس في استخدام هذه الشبكات. - دراسة يوسف بعنوان "استخدام مواقع التواصل الاجتحاعي وأثره علن التحصيل الدراسي

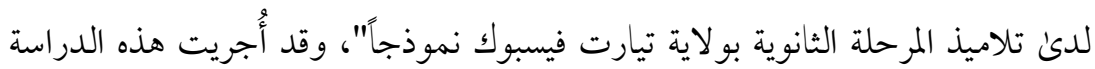

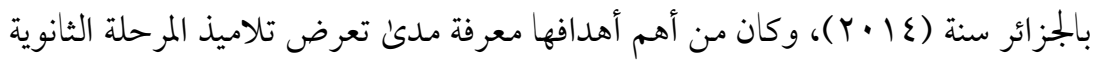
لمواقع التواصل الاجتماعي وبالتحديد موقع فيسبوك وتأثيرها علن تحصيلهم الدراسي والعلمي. وقد توصلت الدراسة إلى أن فيسبوك ساهم في انخفاض المستوى الدراسي لأكثر من نصف أفراد العينة نتيجة الاستخدام المفرط للموقع، إلا أن فيسبوك ساهم في تطوير مستوئ اللغة لدئ التلاميذ. - دراسة الهزاني بعنوان "فاعلية الشبكات الاجتماعية الإلكترونية في تطوير عملية التعليم

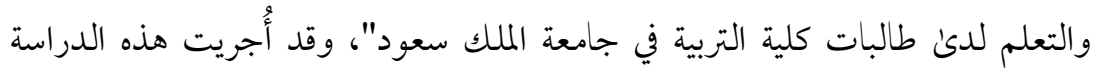

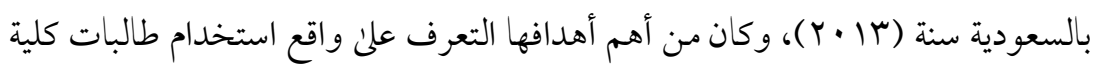
التربية للشبكات الاجتماعية في عملتي التعليم والتعلم، وتركز الدراسة على استخدام الشبكات الاجتماعية في تطور تعلم الطالبات. وقد توصلت الدراسة إلى أن ما يفوق (v0٪) من عينة البحث وجدت أن الشبكات الاجتماعية ساهمت في اثراء الحصيلة المعرفية في التخصص لديهن، كما أظهرت النتائج مدى أهمية هذه الشبكات في التواصل وانشاء مجموعات بحثية وعلمية. - دراسة الدحدوح بعنوان "تصور مقترح لتوظيف الشبكة الاجتماعية فيسبوك في الجماعات

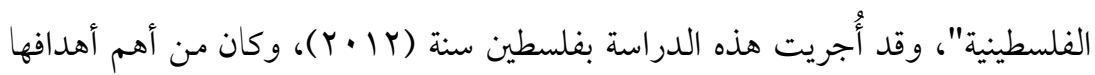


اقتراح تصور لتوظيف موقع فيسبوك في الجامعات الفلسطينية. من خلال دراسة واقع استخدام كلٍ من الطلبة والأكاديميين بالإضافة إلى واقع استخدام إدارة الجامعات الفلسطينية. وقد توصلت الدراسة إلى أن إدارة الجامعات الفلسطينية تستخدم فيسبوك بنسبة (101\%) لأغر اض العلاقات العامة، و (7 \%) للأغراض الأكاديمية. كما أن الطلبة أكثر نشاطاً علن فيسبوك من الأكاديميين، وانهم علن استعداد لاستخدامها في العملية التعليمية، في حين يُعرض الأكاديميين علن هذا. وفي ضوء نتائج الدراسة قام الباحث بوضع التصور المقترح.

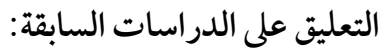

تعقيباً علن جُملة الدراسات السابقة السالف ذكرها، يتضح أن هذه الدراسات قد تعددت واختلفت باختلاف الأهداف التي سعت لتحقيقها، واختلاف البيئات التي أُجريت فيها، فمن هذه الدراسات ما تناول موضوع توظيف شبكات التواصل الاجتماعي في العملية التعليمية كدراسة

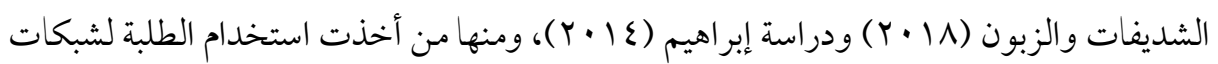

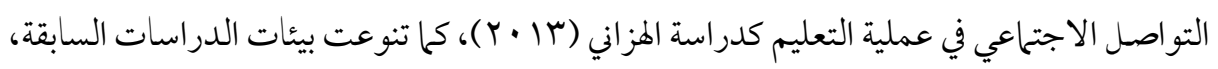

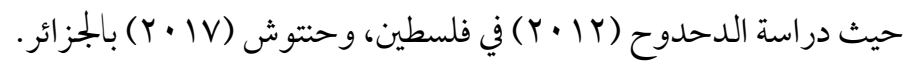
وقد اتفقت الدراسة الحالية مع الدراسات السابقة من حيث المنهج الذي استخدم، وهو المنهج الوصفي التحليلي، ومن حيث الأداة التي جمعت بها البيانات وهي الاستبانة، ومن حيث مجتمع الدراسة فقد تشابهت هذه الدراسة في اختيارها للمجتمع من الطلبة الجمامعيين مع دراسة الشديفات والزبون

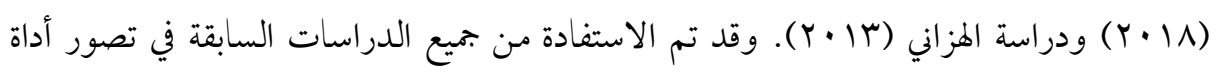
الدراسة الحالية، وإثر اء الأدب النظري. وما تميزت به الدراسة الحالية عن الدراسات السابقة أنها وحسب علم الباحثان تعتبر أول الدراسات العربية التي تناولت موضوع استخدام شبكات التواصل الاجتماعي في تفعيل التواصل الأمثل بين الكلية وطلابها، بالإضافة إلى أنه قد أُجريت في بيئة مغايرة وهي دولة ليبيا.

الإطار النظري للدراسة 


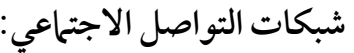

شبكات التواصل الاجتماعي مصطلح ينطبق علن عدد من المواقع الالكترونية علن الشبكة

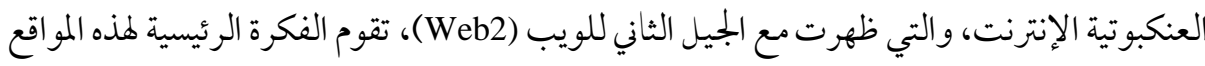

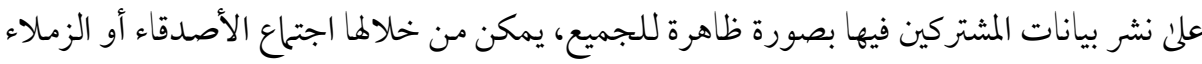

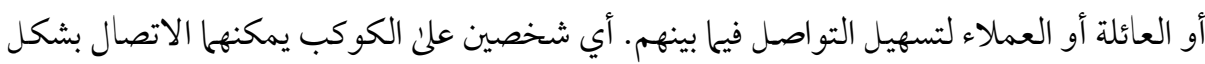

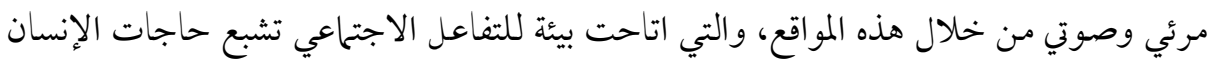

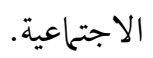

يختلف تعريف شبكات التواصل الاجتاعي من باحث إلى أخر، فيعرف الخبراني (Y + Y)

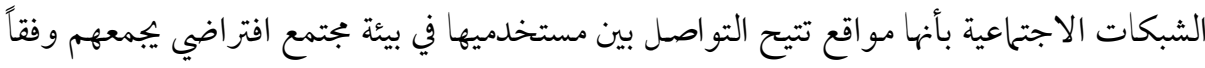
لاهتمامتهم أو انتحاءاتهم (بلد- جامعة - شركة)، يتم ذلك بواسطة خدمات التواصل التهل المباشر كإرسال

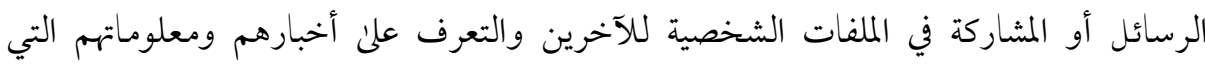

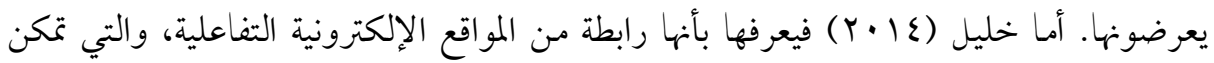

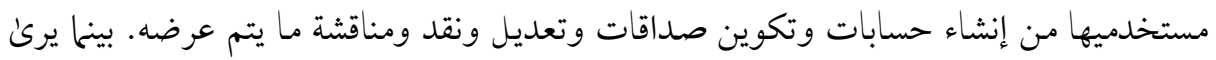
الشرهان (r.r) أنها بجموعة من الشبكات العالمية المتصلة بملايين الأجهزة حول العالر، لتشكل

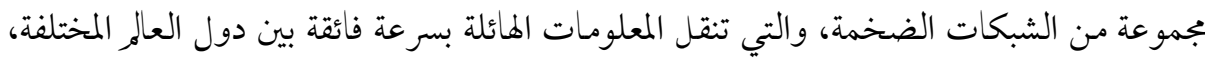

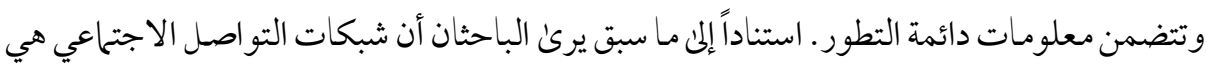

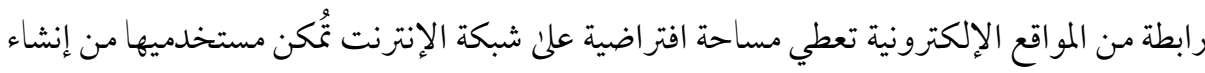
حسابات خاصة بهم، وتقدم لهم خدمات مثل ارسال واستقبال الرسائل والصور والفيديوهات والملفات والمقاطع الصوتية، وتعزز التواصل فيما بينهم، وتمكنهم من متابعة الأحداث أول بأول.

إحصائيات استخدام شبكات التو اصل الاجتلاعي:

\section{http://dx.doi.org/10.29009/ijres.4.2.7}




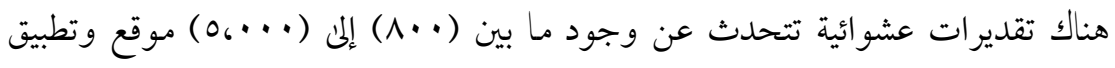

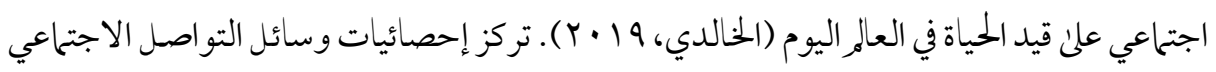
العامة لعام (19 • (Y) علن إحصائيات الشبكة الاجتماعية من مختلف الجوانب، والجدول رقم (1) (إحصائيات مستخدمون الشبكات الاجتماعية لسنة 19 • (Y) المبين أدناه، يوضح لنا إحصائيات للشبكات الاجتماعية الكبرئ الأكثر استخداماً على مستوئ العالر لسنة (19 (Y)، تشمل الإحصائيات

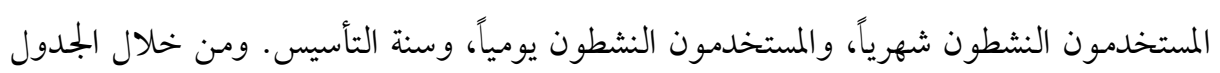
نلاحظ أن موقع فيسبوك يتبوا المرتبة الأولم، حيث يصل عدد مستخدميه إلى Y , r مليار شهرياً، و ع , 1 مليار يومياً.

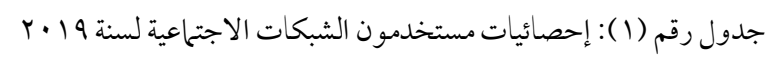

\begin{tabular}{|c|c|c|c|c|}
\hline المستخدمون النشطون يومياً & المستخدمون الثطون شهرياً & سنة التأسيس & المواقع الاجتاعية & الترتيب الت \\
\hline $1, \varepsilon \cdots, \cdots, \cdots$ & $r, r \cdots, \cdots, \cdots$ & $r \cdots \varepsilon$ & Facebook & الأول ل \\
\hline$r \cdot, \cdots, \cdots$ & $1,0 \cdots, \cdots, \cdots$ & $r \cdots o$ & YouTube & ال الثاني \\
\hline$o \cdots, \cdots, \cdots$ & $\wedge \cdots, \cdots, \cdots$ & $r \cdot 1$. & Instagram & الثالث \\
\hline$r r \cdot, \cdots, \cdots$ & $v \cdots, \cdots, \cdots$ & $r \cdots q$ & What's App & الرابع الر \\
\hline- & $r q 0, \cdots, \cdots$ & $r \cdot 11$ & Google + & الخامس \\
\hline $1 \cdots, \cdots, \cdots$ & r & $r \cdots r$ & Twitter & 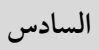 \\
\hline $\operatorname{Iv} \wedge, \cdots, \cdots$ & $r \cdot 1, \cdots, \cdots$ & $r \cdot 11$ & Snap chat & السابع \\
\hline
\end{tabular}

المصدر: Dustin TV Social Media Statistics, 2019

\section{نموذج الدراسة (فيسبوك):}

كما ذكرنا سالفاً أن موقع فيسبوك هو أكثر شبكات التواصل الاجتهاعي شهرةً واستعمالاً علن المستون العالمي، هذا بالإضافة إلى أنه هو الموقع الرائج استعماله فيها بين الكلية (قيد الدراسة) وطلابها. بحكم أن الأولى لماصفحة رسمية على موقع فيسبوك يتم استع|لها من قبل إدارة الكلية بغية الاتصال

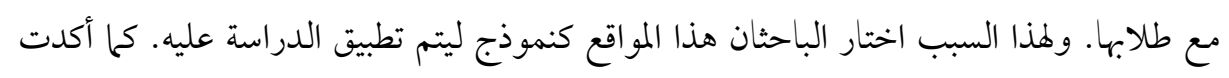


العديد من الدراسات أن أهم الدوافع المحققة من استخدام طلبة الجامعة لموقع فيسبوك تمثلت في الاتصالات بوجه عام، والبحث عن أصدقاء جدد، وإرسال رسائل للأصدقاء، والبقاء علن اتصال مع الزملاء القدامئ، والبحث عن زملاء الدراسة، والاستفسار عن المقررات الدراسية، ووضع خطط مع الطلبة الآخرين، ووضع حلول لمشكلات، وإرسال وقراءة رسائل البريد الإلكتروني، وقضاء الوقت والتسلية، والحصول علن معلومات عن الكلية أو الجامعة التي ينتمون إلهيا، ومشاركة الآخرين للمعلومات حول أحداث المجتمع، والبقاء علن اتصال مع الزملاء خلال فترة الاجازة، وتبادل المذكرات والمحاضرات الجامعية مع الزملاء، والاشتراك في مجموعات أكاديمية لتبادل الآراء حول خختلف القضايا العلمية، ومراسلة الزملاء بغرض البحث عم معلومات علمية علن شبكة الإنترنت، وتبادل الخبرات الجامعية والعملية، وتبادل المعلومات الأكاديمية، وإبداء الاقتراحات، وتكوين صداقات جديدة في الجامعة التي التحقوا بها، والتعاون في انجاز الأعمال المشتركة، والتواصل مع معلميهم وتسليم الأعمال واستلام التعليقات، والثقافة العامة المتنوعة، ومعرفة الأخبار السياسية والاجتماعية" (المخلافي، 1) • Y، ص بع |). وبذلك يمكن القول بأن استخدام شبكة التواصل الاجتماعي فيسبوك أصبح أمراً ضرورياً لدئ الطلبة الجامعيين. إحصائيات فيسبوك في ليبيا: ذكرت الإحصائية الصادرة عن كلية دبي للإدارة الحكومية أن عدد مستخدمي فيسبوك في ليبيا يفوق مليوني مستخدم حتى العام (Y P IV)، وبنسبة (9)٪) من السكان، في حين بلغت نسبة نمو

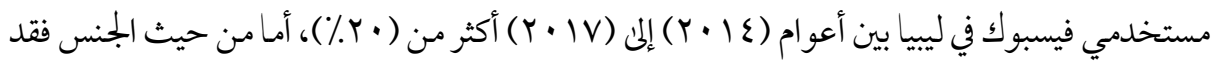

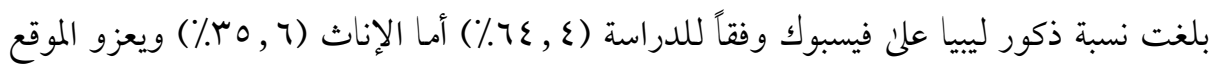
أسباب هذه الفجوة إلى القيود الاجتماعية التي تواجه المرأة. وبالنسبة للفئات المستخدمة فإن فيسبوك

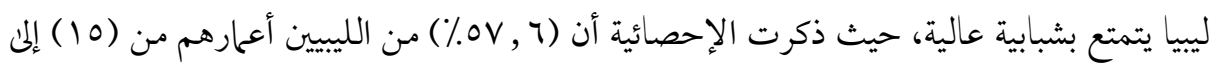

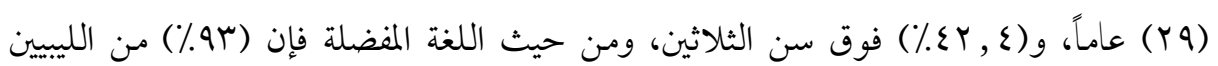
يستخدمون اللغة العربية، بينما (V, ؟ ٪\%) يستخدمون اللغة الإنجليزية كو اجهة لفم، والباقي يستخدمون 
عبدالسلام عبدالحميد عمر ان \& إياد علي مفتاح بالحاج المجلد (4) العدد (2) 2021م عبدم عمران

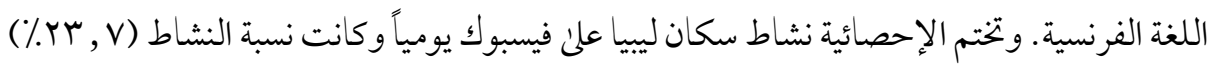

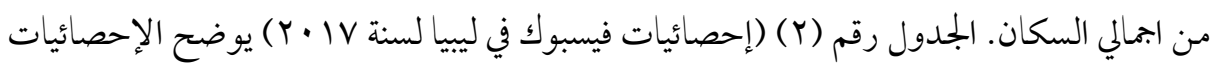
الواردة في الدراسة.

\begin{tabular}{|c|c|c|}
\hline النسبة ٪ & \multicolumn{2}{|c|}{ الـمتغيــر } \\
\hline$\%\urcorner \varepsilon, \varepsilon$ & الذكور & \\
\hline$\%$ ro, 7 & الإناث & الجنس \\
\hline$\% 1 \ldots$ & الإجمالي & \\
\hline$\%$ ov, 7 & من 10 إلى 9 سنة & \\
\hline$\% \varepsilon r, \varepsilon$ & أكثر من • r سنة & العمر \\
\hline$\% 1 \ldots$ & الإجمالي & \\
\hline$\% 9 r$ & اللغة العربية & \\
\hline$\%$ ४ , V & اللغة الإنجليزية & اللغة المستخدمة \\
\hline$\% \cdot r$ & اللغة الفرنسية & \\
\hline$\% 1 \cdots$ & الإبمالي & \\
\hline
\end{tabular}

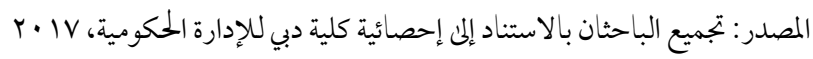

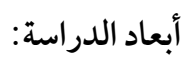
تتمثل أبعاد استخدام صفحة الكلية علن موقع فيسبوك للتواصل مع طلابها في الخصوصية، والنشر، والاستجابة. يقصد بالخصوصية هو الحفاظ علن سرية المعلومات المتعلقة بالطلبة ومدئ مستوى سريتها. ويقصد بالنشر هو تحميل المعلومات والمنشورات المتعلقة بأخبار الكلية ونشاطاتها، وكذلك تلك التي تتعلق بالطلبة وسير الدراسة والامتحانات وغيرها من حيث آلية التحميل ومنهجيتها وتوقيتها وانتظامها. أمـا الاستجابة فيقصد بها مدى تجاوب الكلية لما يقدمه الطلبة من وني استفسارات وتعليقات وملاحظات تتعلق بسير الدراسة والمشاكل التي تعتريها، ووجهات نظر الطلبة 
حيال بعض الأمور التي تتعلق بسير العملية التعليمية. والشكل رقم (1) (أبعاد الدراسة المستخدمة لقياس مستوئ استخدام الصفحة) يوضح أبعاد قياس استخدام الصفحة. شكل رقم (1): أبعاد الدراسة المستخدمة لقياس مستوئ استخدام الصفحة

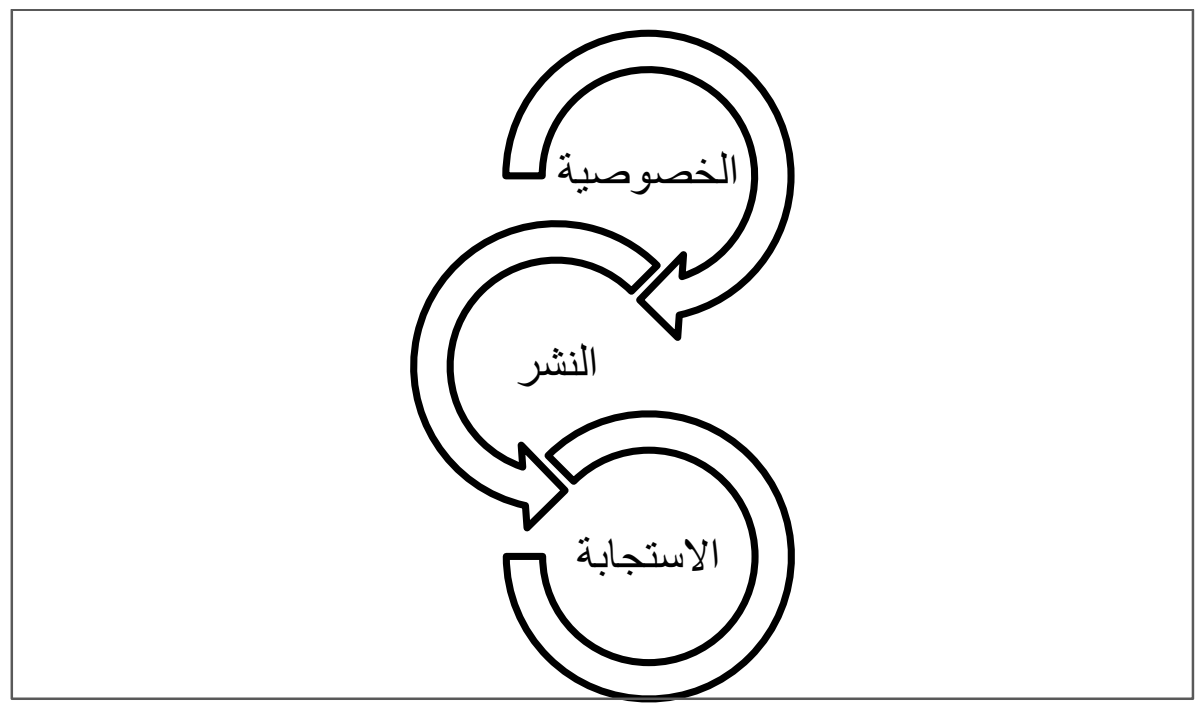

المصدر: إعداد الباحثان

الجانب العملي للدراسة

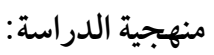

الغرض من هذه الدراسة هو استجلاء وجهات نظر طلبة كلية العلوم الإدارية والمالية التطبيقية طر ابلس إزاء استخدام شبكة التو اصل الاجتماعي فيسبوك في تفعيل التو اصل الأمثل بينهم وبين الكلية، وبذلك استخدم الباحثان المنهج الوصفي التحليلي باعتباره الأنسب منهجياً لتحليل مثل هذه المو اضيع.

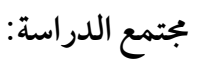
تكون بجتمع الدراسة من جميع طلبة كلية العلوم الإدارية والمالية التطبيقية طرابلس والبالغ عددهم (90،19) طالب وطالبة من مختلف التخصصات العلمية بالكلية (المحاسبة، مصارف 
واستثمار، إدارة الأعمال)، حسب إحصائيات المسجل العام للكلية وذلك خلال الفصل الدراسي ربيع

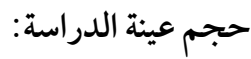

قام الباحثان بتحديد حجم عينة البحث بحيث تمثل المجتمع الأصلي من خلال استخدام مدخل

$$
\text { رابطة التربية الأمريكية وفق المعادلة الاتية: }
$$

حيث n = حجم عينة الدراسة، N = حجم مجتمع الدراسة، P = نسبة المجتمع واقترح

(Kergcie \& Morgan, 1970)

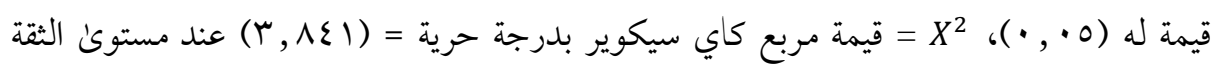
(90 , • ). ووفق هذه المعادلة يمكن أن نصل إلى حجم عينة الدراسة كالاتي:

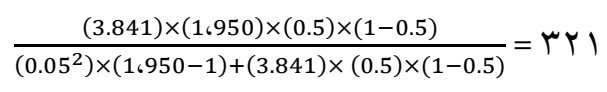

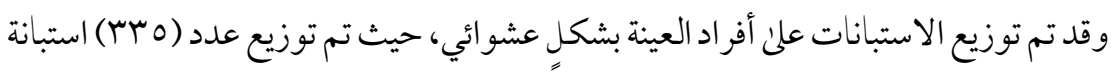

علن طلبة الكلية مراعاةً للفاقد والتالف، أسترد منها (YYY) استبانة، منها (Y) تالفة، و (Y) غير مستوفات لشروط الأسئلة المحورية كما هو مبين في الجدول رقم (r) (الأسئلة المحور المتعلقة بالدراسة)، ليصبح إجمالي عدد الاستبانات التي تمثل عينة الدراسة (YYY)، وبمعدل استجابة

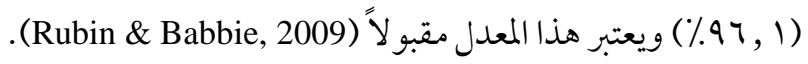
وبالنظر إلى الجدول رقم (Y) المتعلق بالأسئلة المحورية يتضح أن نسبة (99٪) من عينة الدراسة لديهم حساب علن شبكة التواصل الاجتماعي فيسبوك، ونسبة ( • (1\%) من عينة الدراسة علن علم بو جودصفحة للكلية علئ شبكة التو اصل الاجتماعي فيسبوك، وأن ما نسبته (99٪) من عينة الدراسة يتابعون صفحة الكلية على شبكة التواصل الاجتماعي فيسبوك، الأمر الذي يؤكد رغبة الطلبة في التواصل عبر شبكة التواصل الاجتماعي فيسبوك، ويستدعي البحث عن سبل جعل هذه الوسيلة للتو اصل أكثر فعالية للوصول إلى النتائج المرجوة من الدراسة. 
جدول رقم (r) : الأسئة المحورية المتعلقة بالدراسة

\begin{tabular}{|c|c|c|c|}
\hline ت تكرار (لا) & 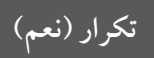 & 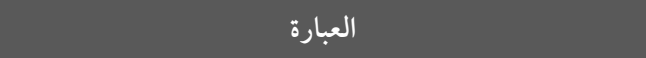 & ر. س \\
\hline r & TrY & هل لديك حساب علئ شبكة التواصل الاجتماعي فيسبوك؟ & 1 \\
\hline . & TrE & هـل تعلم بو جود صفحة للكلية على شبكة التو اصل الاجتماعي & $r$ \\
\hline r & MYY & هل تتابع صفحة الكلية على شبكة التواصل الاجتماعي فيسبوك؟ & $r$ \\
\hline
\end{tabular}

\section{خصائص عينة الدراسة:}

يُظهِهر الجحدول رقم (ع) (توزيع خصائص عينة الدراسة حسب متغيري الجمنس والتخصص)

الخصائص الديموغر افية لعينة الدراسة، و البالخ عددهم (YrY) مفردة، وقد تم استخر اج التكرارات والنسب المئوية لوصف إجابات العينة نحو الفقرات على النحو التالي.

\begin{tabular}{|c|c|c|c|}
\hline النسبة & التكرار & المجموعات & المتغير \\
\hline$\% \varepsilon r, 0$ & Irv & الطلبة الذكور & \multirow{3}{*}{ الجنس } \\
\hline$\%$ V , o & 110 & الطلبة الإناث & \\
\hline$\% 1 \ldots$ & MYY & الإجمالي & \\
\hline$\%$ or, o & 179 & المحاسبة & \multirow{3}{*}{ التخصص } \\
\hline$\% \varepsilon \varepsilon, 0$ & vq & المصارف والاستثمار & \\
\hline \% & $\vee \varepsilon$ & إدارة الأعمال & \\
\hline$\% 1 \ldots$ & MYY & الإجمالي & \\
\hline
\end{tabular}

المصدر: إعداد الباحثان

من الجدول السابق يتضح ارتفاع نسبة الطلبة الإناث (0V,ov٪) مقابل الطلبة الذكور

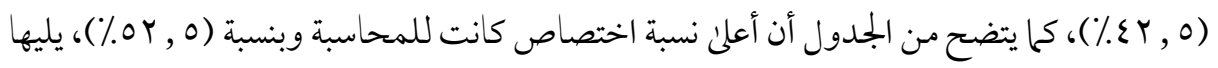
كلاً من المصارف والاستثمار، وإدارة الأعهال وينسبة (0, ع ب\%)، (سץ\%) على التو الي. 
تعد الاستبانة الأداة الرئيسية المستخدمة في الوصول إلى البيانات المتعلقة بتساؤلات الدراسة، فقام الباحثان بتصميم استبانة أعدت خصيصاً لغرض الدراسة، وقد تم تقسيم الاستبانة إلى قسمين رئيسيين و هما:

القسم الأول: ويحتوي علن شقين، الشق الأول متعلق بالأسئلة المحورية والتي يشترط الاجابة عليها بنعم قبل الشروع في الاجابة علن القسم الثاني من الاستبانة، وذلك لكونها مرتبطة ارتباطاً وثيقاً باستعمال فيسبوك كوسيلة للتو اصلـ أما فيما يتعلق بالشق الثاني من القسم الأول للاستبانة فهو يحتوي علن البيانات المتعلقة بخصائص عينة الدراسة (الجنس، التخصص). القسم الثاني: خصص لاستجلاء وجهات نظر الطلبة حيال استخدام صفحة الكلية علن موقع فيسبوك في تفعيل التواصل بينهم وبين الكلية، وللقيام بذلك أعتمد الباحثان ثلاث أبعاد يتم قياس مستوى استخدام الصفحة من خلالها، والمتمثلة في الخصوصية والنشر والاستجابة. وقد اشتملت الصورة الأولية للاستبانة على (IV) عبارة موزعة على أبعاد قياس مستوكي استخدام صفحة الكلية، ولقياس مستوئ استخدام الصفحة تم استخدام مقياس مقياس ليكرت

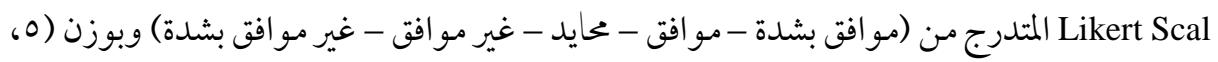
ع ، ؟، ؟، ( ) علن التو المي، ولقد تم تحديد المحك المعتمد في الدراسة بواسطة حساب المدئ بين الدرجات

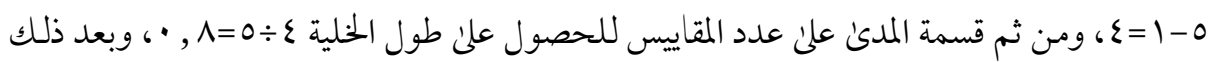

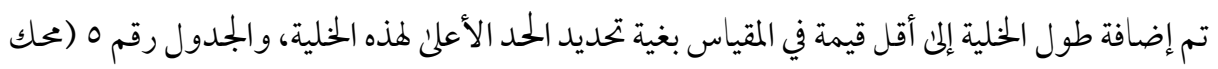
الدراسة) يوضح ذلك.

جدول رقم (0) : محك الدراسة

\begin{tabular}{|c|c|c|c|}
\hline المستوى التقديري & المتوسط المرجح & الدرجة & الر أي \\
\hline ضعيف جداً & $1, \wedge \cdot-1, \cdots$ & 1 & غير موفق بشدة \\
\hline ضعيف & $r, r \cdot-1, \wedge$. & r & غير موافق \\
\hline متوسط & $r, \varepsilon \cdot-r, \tau \cdot$ & r & محايد \\
\hline
\end{tabular}




\begin{tabular}{|c|c|c|c|}
\hline المستوى التقديري & المتوسط المرجح & الدرجة & الر أي \\
\hline مرتفع & $\varepsilon, r \cdot-r, \varepsilon \cdot$ & $\varepsilon$ & موافق \\
\hline مرتفع جداً & $0, \cdots-\varepsilon, r$. & 0 & موافق بشدة \\
\hline
\end{tabular}

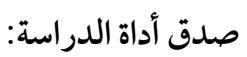

وقد تم التحقق من صدق استبانة الدراسة من خلال (الصدق الظاهري للاستبيان "صدق المحكمين"، وصدق الاتساق الداخلي لعبارات الاستبيان، والصدق البنائي لمحاور الاستبيان).

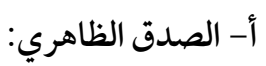

لقد تحقق الباحثان من صلاحية الاستبانة، وذلك بإخضاعها بعد الصياغة الأولية لاختبار الصدق الظاهري، حيث تم عرض الأداة علن بجموعة من المحكمين من ذوي الخبرة والاختصاص، وطلب منهم إبداء ملاحظاتهم وآرائهم حول ملائمة فقرات أداة الاستبانة، ومدى وضوحها، وسلامتها اللغوية، وكذلك اقتراح أو حذف أو دمج الفقرات بها يتناسب مع أغراض أداة الدراسة، وبعد استعادة الأداة من المحكمين تم الأخذ بملحوظاتهم، التي أسفرت عن إعادة الصياغة اللغوية لفقرتين، وبقي عدد الفقرات كما هو . بعد ذلك تم تطبيق الأداة على عينة استطلاعية من خارج عينة الدراسة، تكونت من ستة طلبة مِن كلية العلوم الإدارية والمالية التطبيقية طر ابلس، وتم سؤال العينة عن الصعوبات التي واجهوها في الأداة والفقرات التي لمر يفهموها، وأفاد الطلبة بأن الأداة مفهومة ومشوقة، وبالتالي أصبحت الاستبانة جاهزة لقياس باقي أنواع الصدق.

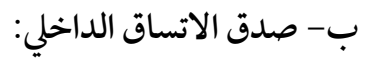
وقد جرئ التحقق من صدق الاتساق الداخلي للاستبيان بحساب معامل ارتباط 'بيرسون' بين درجات كل فقرة من فقرات أبعاد الدراسة والدرجة الكلية للمحور الذي تنتمي إليه، من خلال تطبيقه علن عينة تكونت من ( • ) طالب وطالبة من مجتمع الدراسة ومن خارج عينة الدراسة، والجدول رقم (7) (معامل ارتباط بيرسون بين درجة الفقرة والدرجة الكلية للمحور الذي تنتمي إليه) يعرض نتيجة

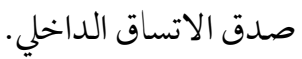

\section{http://dx.doi.org/10.29009/ijres.4.2.7}


جدول رقم (7 ): معامل ارتباط بيرسون بين درجة الفقرة والدرجة الكلية للمحور الذي تنتمي إليه

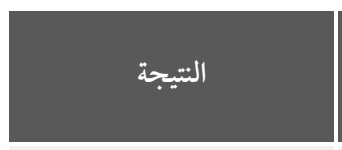

يوجد ارتباط معنوي (دال)

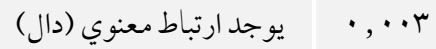

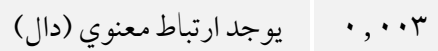

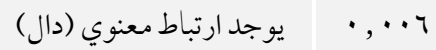

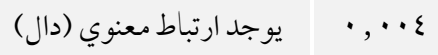

(دال

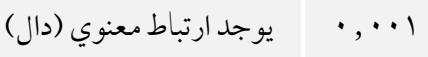

يو جد ارتباط معنوي (دال)

يو جد ارتباط معنوي (دال)

يو جد ارتباط معنوي (دال)

لا يو جد ارتباط معنوي

يوجد ارتباط معنوي (دال)

يوجد ارتباط معنوي (دال)

يوجد ارتباط معنوي (دال)

يوجد ارتباط معنوي (دال)

يوجد ارتباط معنوي (دال)

يوجد ارتباط معنوي (دال)

قيمة الدلالة

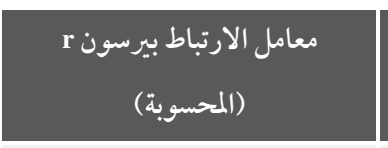

***, $79 \varepsilon$

***, orv

***, or $\varepsilon$

***. , $\{9 \varepsilon$

***, $01 r$

***, 797

***, ov1

***, , $\wedge$ r

***,,$\wedge £$

***, $\wedge \varepsilon 0$

$$
\text { • }
$$

***, TVI

*** , Үイ

***,$\wedge \varepsilon r$

***, $\vee \vee\urcorner$

***, 90r

****, $\wedge r 7$

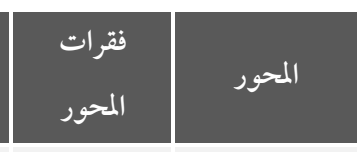

1

r

r

$\varepsilon$

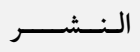

0

7

v

$\wedge$

9

1.

11

Ir

ir

18

10

17

IV

\section{الاستــجابـة}

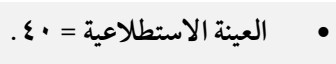

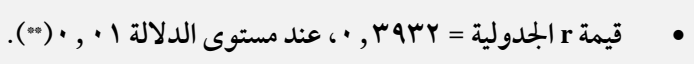

• ق اعدة: إذا كانت r المحسوبة > الجدولية، فإنه يوجد ارتباط معنوي. المصدر: إعداد الباحثان

من نتائج الجمدول السابق نجد أن جميع معاملات ارتباط بيرسون بين فقرات محور (النشر والاستجابة والخصوصية) والمحور الذي تنتمي إليه دالة إحصائياً عند مستوى الدلالة (1 · , )، 
باستثناء الفقرة رقم (11)، كونها غير دالة إحصائيًا لذا تم حذفها، وبذلك يأتي الحد الأدنى لمعاملات الارتباط عند الفقرة رقم (ع) بارتباط (ع ع ع , •)، والحد الأعلان لمعاملات الارتباط عند الفقرة رقم

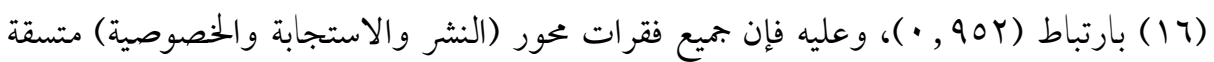
داخلياً مع الدرجة الكلية للمحور الذي تنتمي إليه، مما يثبت صدق الاتساق الداخلي لفقرات محاور الاستبانة.

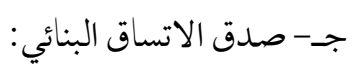
قام الباحثان بحساب صدق الاتساق البنائي للاستبيان بحساب معامل الارتباط 'بيرسون' بين درجة كل محور والدرجة الكلية للاستبيان، بالتطبيق علن نفس العينة المشار إليها عند حساب صدق الاتساق الداخلي، والجمدول رقم (V) (معامل ارتباط بيرسون بين درجة كل محور والدرجة الكلية) يعرض لنا نتيجة الصدق البنائي. جدول رقم (V): معامل ارتباط بيرسون بين درجة كل محور والدرجة الكلية
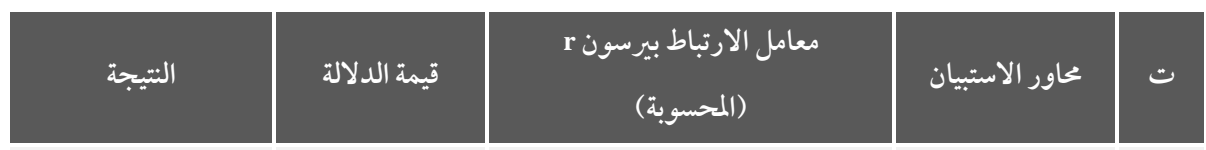

$$
\text { يوجد ارتباط معنوي }
$$

(دال)

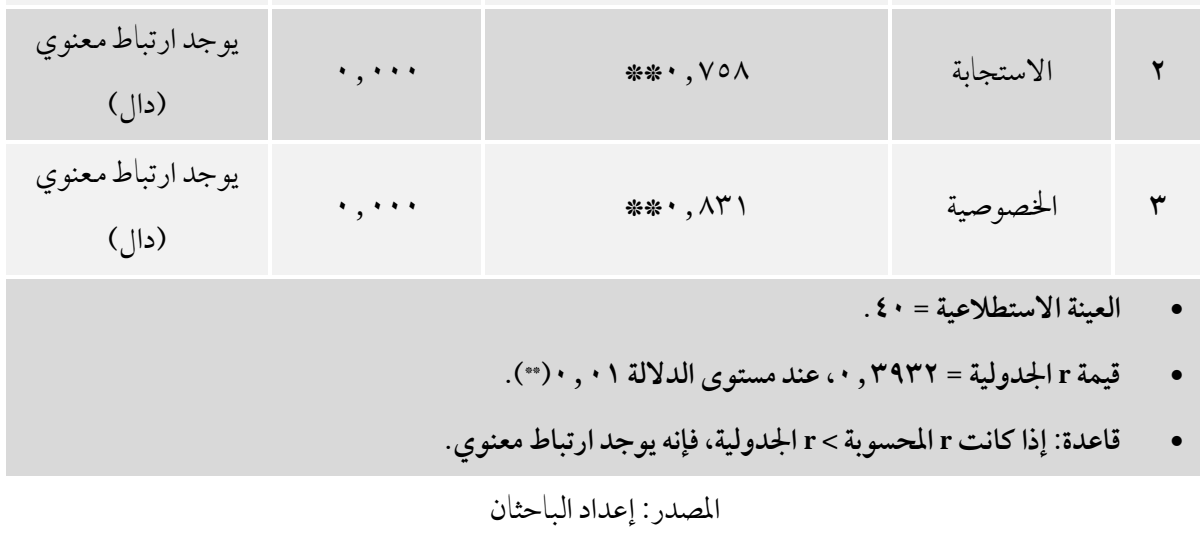

http://dx.doi.org/10.29009/ijres.4.2.7 
عبدالسلام عبدالحميد عمران \& إياد علي مفتاح بالحاج المجلد (4) العدد (2) 2021م عبدم عمبرن

من خلال الجمدول أعلاه نلاحظ أن جميع معاملات الارتباط بيرسون لكل محور (النشر بلغ

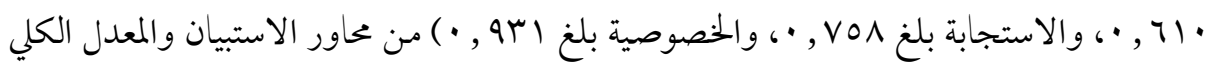
لعبار اته دالة إحصائياً، حيث قيمة r المحسوبة أكبر من قيمة r الجمدولية عند مستوئ الدلالة (1 ب . , · ) ومنه تعتبر محاور الاستبيان صادقة ومتسقة لماوضعت لقياس.

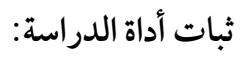

يقصد بثبات الاستبيان، الحصول على نفس النتيجة لو تم إعادة توزيع الاستبيان أكثر من مرة

تحت نفس الظروف والشروط (استقرار النتائج). وللتحقق من ثبات أداة الدراسة، قام الباحثان بحساب معامل الثبات عن طريق معامل الثبات ألفا كرونباخ (Cronbachs Alpha)، وقد تم تطبيقه علن نفس العينة الاستطلاعية عند حساب الصدق، والجدول رقم (^) (قيم معامل ألفا كرونباخ لمحاور الدراسة) يوضح معاملات ثبات أداة الدراسة. جدول رقم (^): قيم معامل ألفا كرونباخ لمحاور الدراسة

\begin{tabular}{|c|c|c|c|c|}
\hline \multicolumn{2}{|c|}{ معامل ألفا كرونباخ } & \multirow{2}{*}{ محاور الاستبيان } & \multirow{2}{*}{\multicolumn{2}{|c|}{ ت }} \\
\hline القيمة & عدد العبارات & & & \\
\hline$\cdot, 7 \cdot 1$ & v & النشر & 1 & \\
\hline$\cdot, \wedge \tau \mu$ & 0 & الاستجابة & r & \\
\hline$\cdot, \wedge \vee \backslash$ & $\varepsilon$ & الخصوصية & r & \\
\hline د دثبات عال، وكلم| & ت ترب من الو & على عدم وجود & & • \\
\hline
\end{tabular}
المصدر: إعداد الباحثان

نلاحظ من خلال الجدول أعلاه أن معامل ألفا كرونباخ يتراوح ما بين (1 • ؟ , • ) كحد أدنى وبين ( NVI , • ) كحد أعلان، و تشير هذه القيم إلى أن الاستبيان يتمتع بمستوى عالي من الثبات، إذ أوصئ

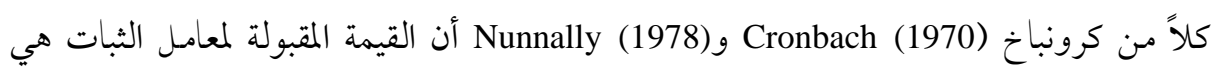




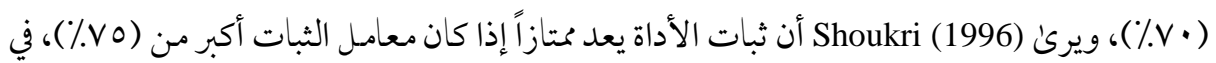
حين يرى الباحث (2000) Sekaran وكلاً من الباحثين (2002) Amir \& Sonderpandian إن النسبة المقبولة لمعامل ألفا كرونباخ هي ( • ٪\%). كما قام الباحثان بإجر اء تحليل لفقر ات الاستبانة، وذلك للتأكد إذا ما كان تأثير حذف أي فقرة من فقرات الاستبانة على كل من قيمة معامل ألفا كرونباخ، حيث تبين أن إجراء الحذف علن أي فقرة لا ينتج عنه تغيير إيجابي علن معامل ألفا كرونباخ. ومن خلال قياس صدق وثبات أداة الدراسة، نستنتج أن أداة الدراسة التي أعددناها لمعالجة المشكلة المطروحة هي صادقة وثابتة في جميع فقراتها.

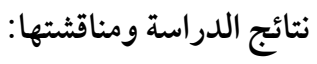
في هذا الجزء من الدراسة يجرى عرض نتائج التحليل الإحصائي للبيانات والاجابة على تساؤلات الدراسة، وتحقيق أهدافها. - - نتائج السؤال الفرعي الأول والذي ينص علن: "ما مستوى توظيف الكلية لصفحتها علن

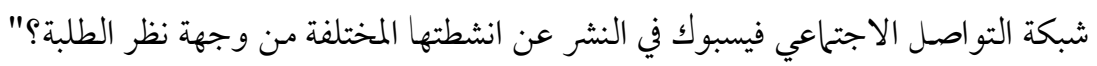
والجدول رقم (9) يستعرض المتوسطات وترتيبها والانحر افات المعيارية الخاصة باستجابات

$$
\text { أفراد العينة لفقرات محور النشر. }
$$

جدول رقم (9) : المتوسط الحسابي والانحراف المعياري لوصف إجابات العينة نحو النشر

\begin{tabular}{|c|c|c|c|c|c|}
\hline 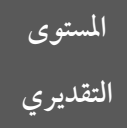 & 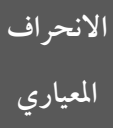 & المسابي - المتوسط & الفقرة & الفقرة & 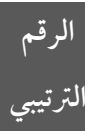 \\
\hline مرتفع جداً & $\cdot, \wedge \cdot$ & $\varepsilon, \varepsilon$. & متابعة صفحة الكلية وفرت لي الوقت والجها في & $r$ & 1 \\
\hline مرتفع جداً & $\cdot, 71$ & $\varepsilon, r \wedge$ & خلال صفتحتها علن فيسبوك. & $r$ & r \\
\hline مرتفع جداً & $\cdot, \wedge \vee$ & $\varepsilon, \mu_{0}$ & كليه. مل ينشر من أخبار علن صفحة الكلية يعتمد & V & $r$ \\
\hline
\end{tabular}




\begin{tabular}{|c|c|c|c|c|c|}
\hline المستوى & الانجر اف & المتوسط & الفقرة & الفقرة - مقب & الترقيب \\
\hline مرتفع جداً & $\cdot, \wedge \vee$ & $\varepsilon, Y Y$ & تنشر الكلية أنشطتها المختلفة بشكل مستمر عبر & 1 & $\varepsilon$ \\
\hline مرتفع & $\cdot, 9 V$ & $r, q$. & وقهتم صفحة الكلية بنشر أحداث وأخبار الكلية & 0 & 0 \\
\hline 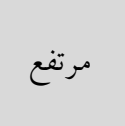 & $1, Y_{1}$ & $r, \& r r$ & سو يو جد مصدر أخر للحصول على أخبار الكلية & $\varepsilon$ & 7 \\
\hline مرتفع & $1,1 \mathrm{~V}$ & $r,\{1$ & لا يوجد قصور في نشر الأحداث على الصفحة. & 7 & V \\
\hline مرتفع & $\cdot, 0\}$ & $\varepsilon, \cdot 1$ & أداة قياس النشر ككل & & \\
\hline
\end{tabular}

يتضح من الجمدول السابق أن مستوكا توظيف الكلية لصفحتها على شبكة التو اصل الاجتماعي

فيسبوك في النشر عن أنشطتها المختلفة "مرتفع"، حيث بلغ المتوسط الحسابي (1 , ع )، والانحراف

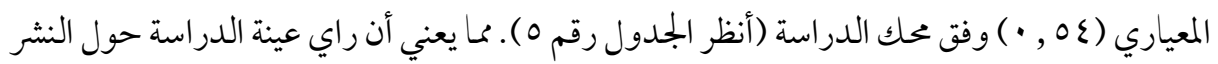
مو افقون. ويعزو الباحثان حصول النشر على مستوئ مرتفع إلى أن الكلية من جانبها ترغب في التو اصل مع الطلبة عبر وسيلة التواصل الاجتماعي فيسبوك لانتشارها الواسع في ليبيا ولسهولة وصول الطلبة إليها، ولتخفيف العبء علن الطلبة في الوصول إلى كل ما يحتاجونه من معلومات عن سير الدراسة والمشاكل التي تعتريها. بالإضافة إلى ذلك، فإن الكلية ترغب في نشر أنشطتها وبرابجها وخططها وإنجاز اتها عبر صفحتها الرسمية علن موقع فيسبوك. والدليل علن ذلك التفعيل والتحديث المستمرين

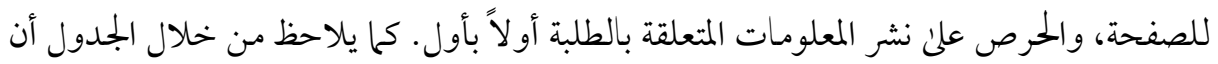
أعلى فقرة في هذا المحور هي الفقرة رقم (Y)، والتي نصت علنى :"متابعة صفحة الكلية وفرت لي الوقت و الجهد في الحصول علن المعلومات الخاصة بالكلية" حيث تحصلت علن مستوى تقديري "مرتفع جداً"، وبمتو سط حسابي (• ع , ع)، و انحر اف معياري (•N , •)، وتعود الموافقة بشدة علئ هذه العبارة من وجهة نظر الباحثان إلى دور كلاً من الكلية والطلبة في استعمال فيسبوك كوسيلة اتصال فيما بينها، حيث 
أن الكلية تحرص علن نشر كل ما يستجد من معلومات وأخبار أولا بأول، وبالمقابل لعبت سهولة استعحال فيسبوك كوسيلة من قبل الطلبة، وانتشار الأجهزة المتخلفة المستعملة في ذلك كالهو اتف الذكية واللوحات (Ipads) وغيرها؛ والتي أصبحت في متناول الطلبة بسبب توفرها ورخص أثمانها نسبياً،

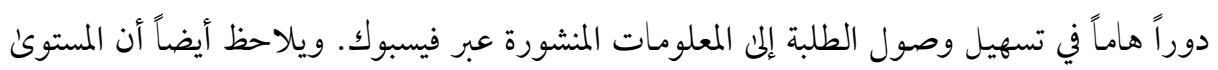
التقديري الذي تم الوصول إليها في الفقرة رقم (7) والتي نصت على: "لا يوجد قصور في نشر

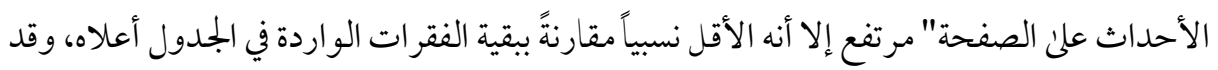

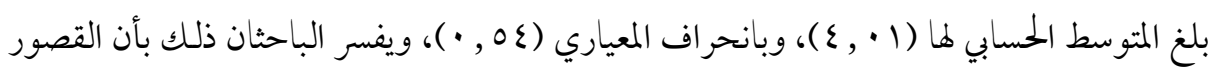
يحدث أحياناً لأسباب تخرج عن إرادة القائمين علن إدارة الصفحة، كتأخر وصول المعلومات أو تعذر الحصول علن إجابات في الوقت المناسب أو عدم التأكد من صحة أو دقة المعلومة المراد نشرها، وهذا

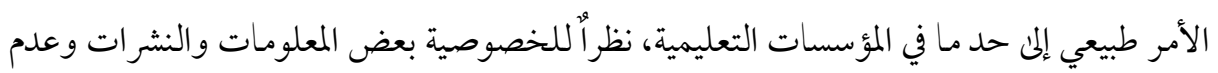
إمكانية الوصول إليها، الأمر الذي قد يظهر للطلبة المتابعين للصفحة كأنه قصور من جانب الكلية. - - - متائج السؤال الفرعي الثاني والذي ينص علن: "مـا مستوكئ استجابة صفحة الكلية على شبكة التو اصل الاجتهاعي فيسبوك للرسائل والاستفسارات التي يقدمها لها الطلبة من وجهة نظر الطلبة أنفسهم؟" والجمدول رقم (• (1) يستعرض المتوسطات وترتيبها والانحرافات المعيارية

$$
\text { والخاصة باستجابات أفراد العينة لفقرات محور الاستجابة. }
$$

جدول رقم ( • 1): المتو سط الحسابي والانحراف المعياري لوصف إجابات العينة نحو الاستجابة

\begin{tabular}{|c|c|c|c|c|c|}
\hline 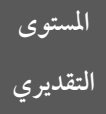 & الاندراف & المتوسط & الفقرة & رقبم & 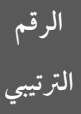 \\
\hline 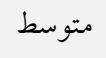 & 1,17 & Y, TV & تقوم صفحة الكلية بالرد على الرسالة التي أقدمها لها. & $\wedge$ & 1 \\
\hline ضعيف & 1,17 & $r, O \wedge$ & تئفاعل صفحة الكلية بالرد على التعليقات الموجهة ها & 1. & r \\
\hline ضعيف & 1,11 & $r, \varepsilon \varepsilon$ & 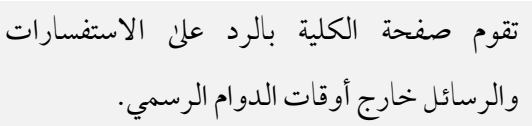 & 11 & $r$ \\
\hline
\end{tabular}

http://dx.doi.org/10.29009/ijres.4.2.7 


\begin{tabular}{|c|c|c|c|c|c|}
\hline المقديري & الانبحراف & المتوسط & الفقرة & الفقرة & 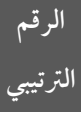 \\
\hline ضعيف & $1,1$. & $r, \varepsilon r$ & فترة وجيزة صفحة الكلية إلى الرسائل التي أرسلها في & 9 & $\varepsilon$ \\
\hline ضعيف & $1,1 Y$ & $r, r$ & تسعى الكلية لتحقيق مطالب الطلبة المرسلة إليها عبر & Ir & 0 \\
\hline ضعيف & $\cdot, 19$ & $r, \varepsilon q$ & أداة قياس الاستجابة ككل & & \\
\hline
\end{tabular}

يتضح من الجلدول السابق أن مستوى استجابة صفحة الكلية علن شبكة التواصل الاجتماعي

فيسبوك للرسائل والاستفسارات التي يقدمها لها الطلبة "ضعيف"، حسب محك الدراسة (أنظر

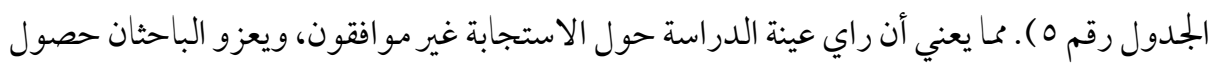
الاستجابة علن مستوىن ضعيف إلى أن القائمين علن إدارة الصفحة غير متفرغين لهذا العمل ولا يتم مكافأتهم على ما يبذلونه من ججهود، ومن ثم تصبح استجابتهم لما يطرح عليهم من أسئلة أو تعليقات في شكل استفسارات تكون حسب أهو ائهم. كما يلاحظ من خلال الجمدول أن أعلا فقرة في هذا المحور هي الفقرة رقم (^)، والتي تنص علن: "تقوم صفحة الكلية بالرد على الرسالة التي أقدمها لها" حيث

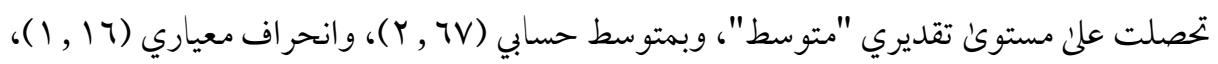
ويرى الباحثان أن سبب حياد هذه الفقرة مرده صعوبة تفاعل القائمين علن إدارة الصفحة مع العدد الهائل من الطلبة والذي يبلغ (90،190) طالب وطالبة، والذي يتطلب وجود فريق عمل قادر علن الاستجابة لكل ما يَرد من استفسارات وغيرها، هذا بالإضافة إلى انطباق ما ورد من أسباب والتي تم ذكرها في قياس الاستجابة ككل. ويلاحظ أيضاً أن المستوى التقديري الذي تم الوصول إليه في الفقرة رقم (r) و التي نصت على: "تسعى الكلية لتحقيق مطالب الطلبة المرسلة إليها عبر بريد الصفحة وإنزاها علن أرض الواقع" ضعيف مثلها مثل بقية الفقرات الواردة في الجدول أعلاه إلا أنها تعتبر

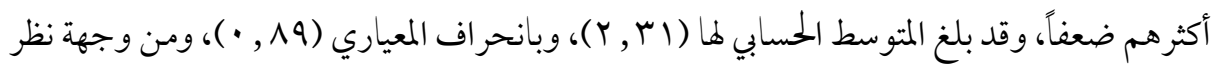
الباحثان يعود السبب إلى أن الإدارة التعليمية بالكلية لا تزال تعمل بالأسلوب التقليدي الذي يغلب 
عليه طابع البيروقراطي في التعامل مع المشاكل التي تعتري الدراسة، هذا بالإضافة إلى أنه يصعب تصنيف الآراء التي ترد في الصفحة ومعرفة النسبة المئوية للإجماع التي يمكن علن ضوئها اتخاذ القرار المناسب حيال المطالب التي يطر حها الطلبة. - - نتائج السؤال الفرعي الثالث والذي ينص علن: " ما مستوئ المحافظة على الخصوصية عندما تتو اصل الكلية مع طلابها عبر صفحتها على شبكة التو اصل الاجتماعي فيسبوك من وجهة نظر الطلبة؟" والجدول رقم (11) يستعرض المتوسطات وترتيبها والانحرافات المعيارية والخاصة باستجابات أفر اد العينة لفقرات محور الخصوصية. جدول رقم (11): المتوسط الحسابي والانحراف المعياري لوصف إجابات العينة نحو الخصوصية

\begin{tabular}{|c|c|c|c|c|c|}
\hline 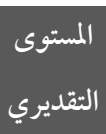 & المعياري - انحراف & المتوسط & 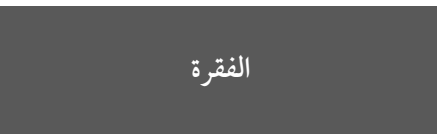 & الفقرة & 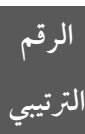 \\
\hline ضعيف & $1,\{\varepsilon$ & $r, O \varepsilon$ & لا أمام اللحنة صفحة المثكلة بالأسماء. بنشر طلب المثول & 17 & 1 \\
\hline ضعيف & 1,17 & $r, \cdot r$ & 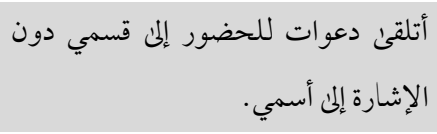 & $1 \varepsilon$ & r \\
\hline ضعيف & $1, r \cdot$ & $r, \cdot 1$ & تتواصل الكلية مع طلابها عبر صفحتها & 10 & $r$ \\
\hline ضعيف & $1,1 \varepsilon$ & $1, \wedge 7$ & بأرقام القيود نتائج الطلبة عبر صفحة الكلية & ir & $\varepsilon$ \\
\hline ضعيف & $\cdot, 99$ & $r, 1$. & قياس الخصصوصية ككل & & \\
\hline
\end{tabular}

يتضح من الجمدول السابق أن مستوئ المحافظة على الخصوصية عندما تتوصل الكلية مع طلابها عبر صفحتها علن شبكة التو اصل الاجتماعي فيسبوك "ضعيفة"، حسب عحك الدراسة (أنظر الجمدول رقم 0)، مما يعني أن راي عينة الدراسة حول الخصوصية غير موافقون، ويعزو الباحثان حصول الخصوصية علن مستون ضعيف لسبب بديهي، كون الكلية تتعامل في أغلب غخاطباتها وتو اصلها مع

\section{http://dx.doi.org/10.29009/ijres.4.2.7}


الطلبة بالأسماء، الأمر الذي يجعل مستون خصوصية الطلبة ضعيف مما قد تؤثر سلباً علن عملية التو اصل بين الكلية وطلابها. كما يلاحظ من خلال الجمدول أن جميع فقرات المحور جاءت بمستون ضعيف، إلا أن الفقرة رقم (r) والتي تنص على: "يتم نشر نتائج الطلبة عبر صفحة الكلية بأرقام

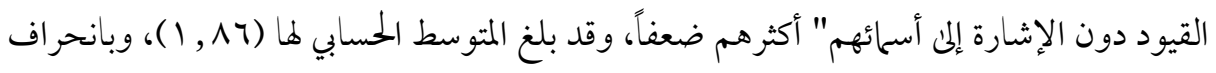
معياري (ع ا , 1 )، ويعلل الباحثان هذه النتيجة بأن القائمين علئ إدارة الصفحة يقومون بنشر ما يتلقونه من معلومات من قبل الإدارات والأقسام المختلفة بالكلية دون أي تغيير، فإن احتوت المعلومات المطلوب نشرها علن أسماء الطلبة، فتظهر في صفحة الكلية كما هي عليه. ويلاحظ أيضاً أن العبارة رقم (7 (1) و التي تنص علن: "لا تقوم صفحة الكلية بنشر طلب المثول أمام اللجنة المشكلة بالأسماء" أقل الفقرات ضعفاً، ويعقب الباحثان علئ سبب ذلك إلى مثل ما ذكر في تعليل الفقرة رقم (r ا )، إلا أن هذه الفقرة خصيصاً تعتبر نادرة الحدوث، ولم تو اجه الأغلبية من المستجوبين، مما جعلها قريبة من المستوكن المتوسط، أي اجماع الحياد.

ولإجابة على السؤال الرئيسي للدراسة و الذي ينص على : "ما مستوئ استخدام شبكة التو اصل الاجتحاعي فيسبوك في تفعيل التواصل الأمثل بين الكلية وطلابها؟" تم أخذ المتوسط الحسابي لجميع فقرات محاور الدراسة، وكانت النتيجة (T +, r)، مما يعني أن مستوئ استخدام شبكة التواصل الاجتحاعي فيسبوك في تعزيز التو اصل بين الكلية والطلبة "متوسط" حسب محك الدراسة (أنظر الجدول (مقم 0)

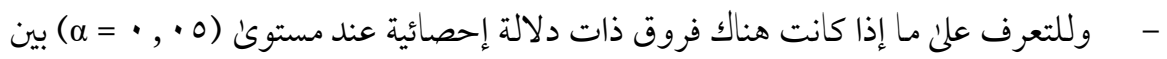
استجابات الطلبة على استبانة التواصل تبعاً لمتغير الجنس. قام الباحثان بإجر اء اختبار الطالب (ت) للعينات المستقلة Independent Samples T-Test، وبعد التأكد من شروط الاختبار كانت التتائج كما هو موضح في الجدول رقم (r I) (المتوسطات الحسابية والانحرافات المعيارية وقيمة (ت) لدلالة الفروق بين متوسطات استجابات الطلبة الذكور ولإناث على مولى

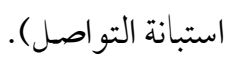


جدول رقم (r ) : المتوسطات الحسابية والانحر افات المعيارية وقيمة (ت) لدلالة الفروق بين متوسطات استجابات الطلبة الذكور الطلبة الإناث علن استبانة التواصل

\begin{tabular}{|c|c|c|c|c|c|c|}
\hline الإحصائية & الاحتحالية & قيمة (ت) & الانحراف & المتوسط & العدد & الجنس \\
\hline \multirow{2}{*}{ غير دال } & \multirow{2}{*}{$\cdot, 79$} & \multirow{2}{*}{1,119} & $\cdot,\{\wedge$ & $r, \cdot q$ & Irv & ذكر \\
\hline & & & $\cdot, \varepsilon ৭$ & $r, r r$ & 110 & أنثى \\
\hline
\end{tabular}

$$
\text { المصدر: إعداد الباحثان }
$$

يتضح من الجدول أعلاه بأن قيمة (ت) بلغت (9 1 , )، عند مستوئ الدلالة (79 , • )، مما يدل علئ عدم وجود فرق ذو دلالة إحصائية بين متوسطات استجابات الطلبة الذكور والطلبة الإناث في الكلية على استبانة التو اصل، ويفسر الباحثان هذه النتيجة بوجود اقبال من الشباب و البنات على حلِ

$$
\text { سواء في استخدام فيسبوك في كوسيلة لتو اصل. }
$$

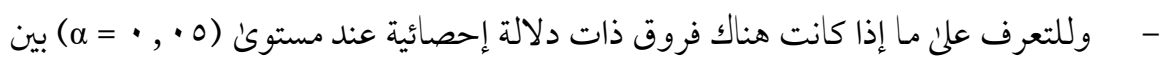
استجابات الطلبة علئ استبانة التو اصل تبعاً لمتغير التخصص (المحاسبة، مصارف واستثلار، إدارة الأعمال)، باستخدام اختبار تحليل التباين الأحادي One-Way ANOVA Test، وبعد التأكد من شروط الاختبار، كانت النتائج كما هو موضح بالجدولين رقم (rا ) (المتوسطات الحسابية والانحرافات المعيارية) ورقم (ع () (نتائج تحليل التباين الأحادي تبعاً لمتغير

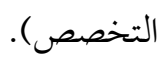

\begin{tabular}{|c|c|c|c|}
\hline الانحر اف المعياري & المتوسط الحسابي & العينة & التخصص \\
\hline$\cdot, \varepsilon 9 r$ & $r, \cdot r v$ & 179 & المحاسبة \\
\hline$\cdot, 01 r$ & $r, 1 \cdot r$ & $\vee 9$ & مصارف واستثار \\
\hline$\cdot, \varepsilon \vee \varepsilon$ & $r$ & $\vee \varepsilon$ & إدارة الأعحال \\
\hline ·, $\{4 r$ & $r, .0 q$ & Mrt & المجموع \\
\hline
\end{tabular}

$$
\text { جدول رقم (r ا ): المتوسطات الحسابية والانحرافات المعيارية }
$$

http://dx.doi.org/10.29009/ijres.4.2.7 
جدول رقم (ع (): نتائج تحليل التباين الأحادي تبعاً لمتغير التخصص

\begin{tabular}{|c|c|c|c|c|c|}
\hline الإحصائية & الاحتحالية & قيمة (ف) & درجات الحرية & بجموع المربعات & المصدر \\
\hline \multirow{3}{*}{ غير دال } & \multirow{3}{*}{ • } & \multirow{3}{*}{$\cdot,\{\rceil$} & r & $\cdot$, YTV & بين المجموعات \\
\hline & & & 119 & $V V, T \wedge V$ & داخل المجموعات \\
\hline & & & rrI & $V V, q 1 \varepsilon$ & الكلي \\
\hline
\end{tabular}

المصدر: إعداد الباحثان

يبين الجلدول رقم (r) (I) عدم وجود تباين ظاهري بين المتوسطات الحسابية والانحرافات

المعيارية، وبالتدقيق في الجمدول رقم (ع ( ) للنظر فيما إذا كان هناك تباين أو فروق، نجد أن قيمة (ف) =

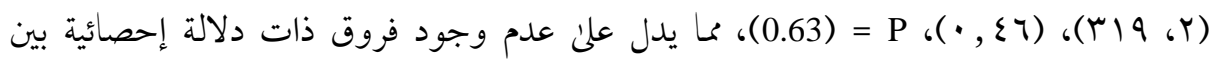
التخصصات العلمية على الدرجة الكلية لمقياس استجابات الطلبة على استبانة التواصل، ويفسر الباحثان هذه النتيجة بأن الطلبة الدارسون في جميع التخصصات العلمية بكافة أنواعها، لا يختلفون في الأهمية والحاجة للتو اصل مع الكلية عبر وسائل التو اصل الاجتماعي المتاحة. التتائج والتوصيات

في هذا الجزء من البحث، سيتم عرض النتائج التي توصلت إليها الدراسة، وكذلك التصور المقترح الذي يضعه الباحثان وفق ما توصلو ا إليه من نتائج. النتائج:

ا. إن ما نسبته ( · (1\%) من عينة الدراسة علئ علم بوجود صفحة للكلية علن موقع فيسبوك، و (99\%) منهم لديهم حساب علن موقع فيسبوك ويتابعون صفحة الكلية علن موقع فيسبوك، وهذه النسبة تؤكدو وجود الركيزة الأساسية لعملية التو اصل بين الكلية وطلابها. r. وفقاً لتقديرات أفر اد عينة الدراسة، فإن مستوكئ استخدام شبكة التو اصل الاجتماعي فيسبوك في تعزيز التواصل بين الكلية والطلبة كانت "متوسط"، أمـا درجات أبعاد استخدام الكلية 
لصفحتها في التو اصل مع طلابها (النشر، الاستجابة، الخصوصية) كانت (مرتفعة، ضعيفة، ضعيفة) علئ التوالي. r. لا توجد فروق ذات دلالة إحصائية عند مستوئ (0 • , • = $\alpha)$ بين استجابات أفراد عينة

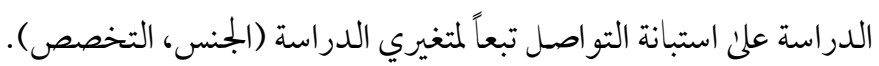
يضع الباحثان التصور المبين أدناه بناءً علن ما توصلا إليه من نتائج.

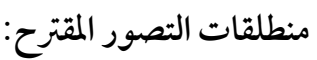
ا. لقد أتضح للباحثَين أن وسائل التواصل الاجتماعي بصفة عامة وعلى الأخص فيسبوك، يمكن أن تكون قاعدة سليمة يبنى عليها برامج التو اصل فيما بين الكلية وطلابها.

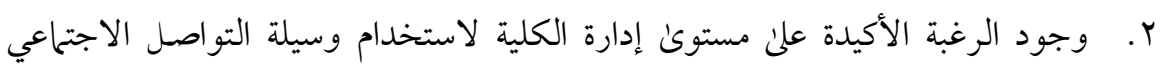
فيسبوك، واستعهال صفحتها علن الموقع كوسيلة للتو اصل.

r. وجود الرغبة الشديدة لدئ الطلبة في استعمال فيسبوك كوسيلة للتو اصل مع الكلية.

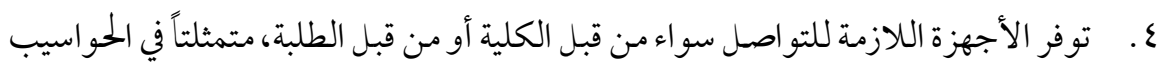
والهو اتف المحمولة الذكية وغيرها.

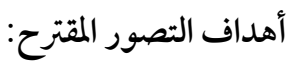

ا. نشر الوعي فيها بين الطلبة، وتوصيل كل ما يخصهم من معلومات ونشرات وغيرها في الوقت

$$
\text { المناسب وبأيسر الطرق. }
$$

r. السعي إلى تطوير وسائل الاتصال فيما بين الكلية وطلابها، والعمل علن تحديث وسائل وطرق الاتصال.

r. الاستفادة من التقنيات المستعملة في الشبكات العنكبوتية لتطوير التعليم بالكلية، وذلك بخلق شبكات تو اصل مع الكليات والجامعات المناظرة في الداخل والخارج، ومحاولة اظهار الكلية بصورة جيدة واشهارها علن المستويين المحلي والدولي. 


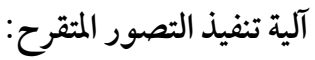

1. تخصيص ممركز خختص بالكلية تناط به مهام إدارة صفحة الكلية، ووسائل التواصل الاجتماعي

المستعملة.

r. يتم تخصيص كادر متفرغ للعمل بالمركز، يمنح صفة رسمية، وتحدد له المهام والاختصاصات من قبل الإدارة المختصة بالكلية.

r. يمنح المكلفون بالعمل في هذا المركز مكافأة-مرتب حسب مالمات تراه الكلية. ع. يتم توفير كافة متطلبات المركز من وسائل اتصال وجمع المعلومات، بالقدر الذي يمكنه من

إدارة الصفحة علن الوجه المطلوب.

ه. يتم ربط مركز التواصل بمركز تقنية المعلومات حتى يتمكن الأول من مو اكبة التطورات

الحاصلة في عالم التكنولوجيا.

7. تتبنى الكلية ضمن سياساتها خصوصية المعلومات المتداولة على الصفحة، ودرجاتها. V. لق رابطة بين اتحاد طلبة الكلية والمركز المختص تساعد على تطوير العلاقة بين الطلبة والمركز، وجعل الصفحة تتمشىل مع رغبات الطلبة ورؤيتهم. ^. قيام الكلية بعقد لقاءات دورية مع اتحاد الطلبة ومركز التواصل لتباحث أحسن السُبل لظهور

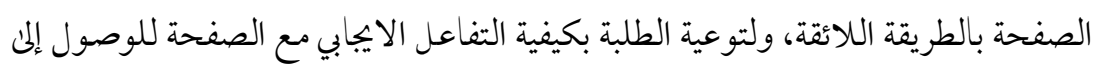
التعاون الأمثل ما بين الطلبة والكلية. 9. يجب ألا يقتصر دور النشر علن ما يتعلق بسير العملية التعليمية ونتائج الامتحانات، بل يتعداه إلى تقديم نصائح للطلبة، والمساهمة في ابراز الأنشطة المختلفة بالكلية. • 1 ـ تقليص عدد الصفحات المتداولة بالكلية إلى صفحة واحدة رئيسية تنبثق عن مركز التو اصل، وذلك للمحافظة علن نشاط متابعي الصفحة الرسمية كي تتمشئ مع سياسة المتبعة في وسيلة

$$
\text { التواصل الاجتهاعي فيسبوك. }
$$


يبين الشكل رقم (Y) أدناه آلية عمل مركز التو اصل و العلاقة بينهم وبين الطلبة والكلية. شكل رقم (Y): غخطط التصور المقترح

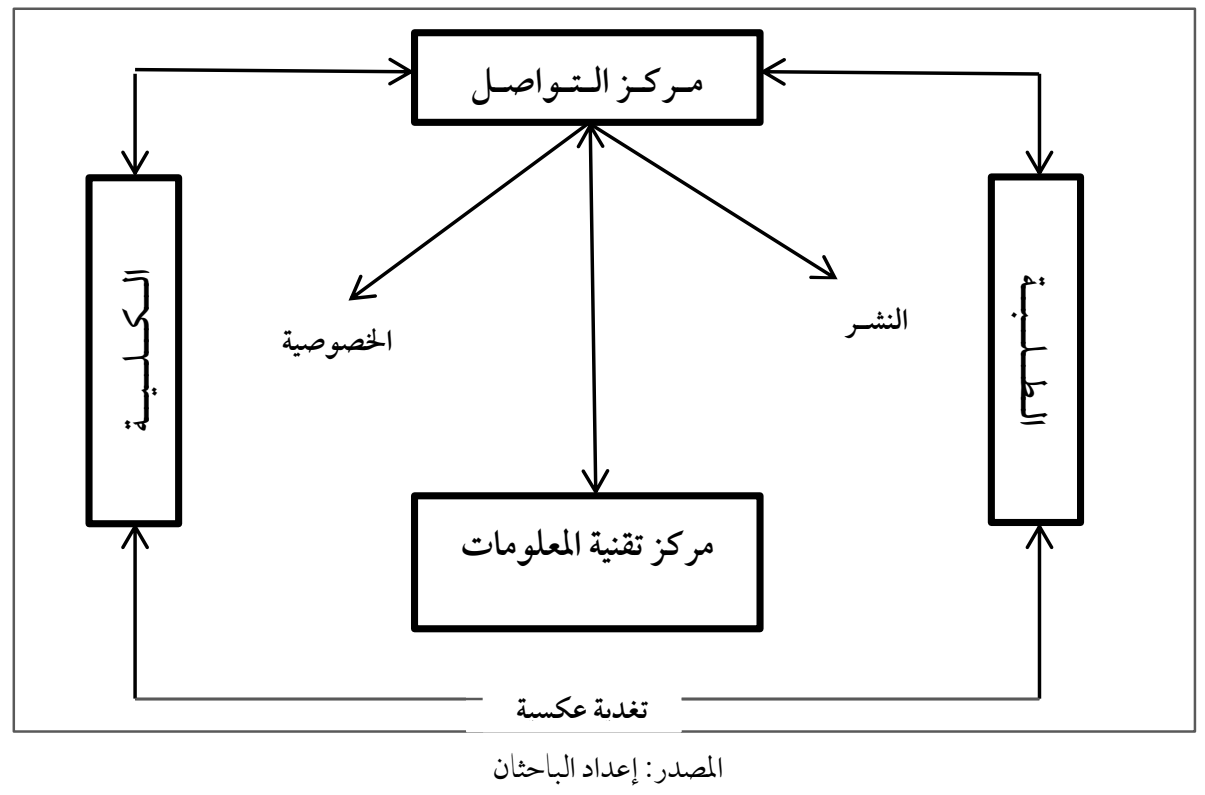




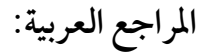

إبر اهيم، خديية عبد العزيز علي (ع) ( ب)، واقع استخدام شبكات التواصل الاجتماعي في العملية التعليمية بجامعات صعيد مصر: دراسة ميدانية مجلة العلوم التربوية ب(Y)، ع الع-

. ₹Vน

أبوخطوة، السيد عبدالمولن السيد، والباز، أحمد نصحي أنيس الشربيني (ع ا • ( )، شبكة التواصل الاجتماعي وأثارها علن الأمن الفكري لدئ طلبة التعليم الجامعي بمملكة البحرين

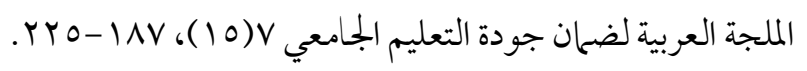

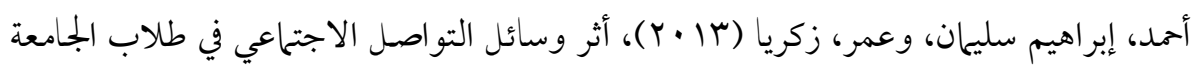

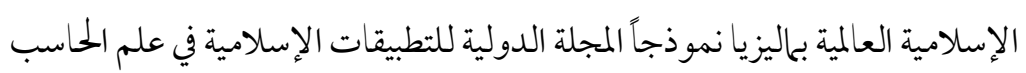

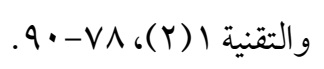

الخالدي، محمد (9 ( )، مو اقع وتطبيقات التو اصل الاجتماعي الأكثر استخداماً حول العلام، مقالة منشورة https://dolphinuz.com/blog/single/45/ مو اقع -التواصل-الاجتماعي

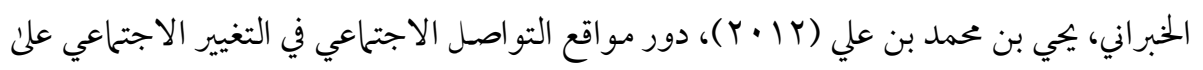
طلاب السنة التحضيرية بجامعة الملك سعود، الرياض: دار المنظومة للنشر.

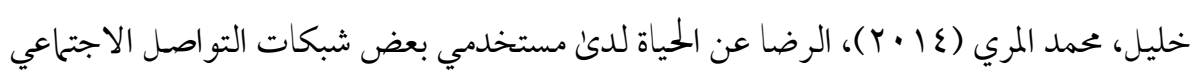
من طلبة كلية التربية بجامعة الزقازيق، المؤتمر العلمي العربي السابع (الدولي الرابع)

$$
\text { التعليم وثقافة التو اصل الاجتماعي. }
$$

الشرهان، جمال عبدالعزيز (r + . r)، الوسائل التعليمية ومستجدات تكنولوجيا التعليم، الرياض: مطابع الحميضي.

الصفحة الرسمية لكلية العلوم الإدارية والمالية التطبيقية طرابلس علن موقع فيسبوك: /https://www.facebook.com/caafs89 
عودة، فراس محمد (ع ( †)، دور شبكات التواصل الاجتماعي في العملية التعليمية المجلة الإلكترونية الإلكتروني.

http://elearning.iugaza.edu.ps/emag/article.php?artID=34

الفتحي، محمد، وهمام، محمد، وخالد، روزهات ويسي، وملوكي، عبدالل، ومنصوري، نديم، والعدوي، محمد (Y (Y)، العنف والسياسة في المجتمعات العربية المعاصرة: ثنائية الثقافة والخطاب، تونس: المركز العربي للأبحاث ودراسة السياسات. المخلافي، حنان عبده فرحان (1) • (Y)، واقع استخدام طلبة كلية التربية في الجامعة الإسلامية العالمية بجاليزيا لشبكة التواصل الاجتماعي فيسبوك واتجاهاتهم نحوها، مجلة جامعة القدس المفتوحة للأبحاث والدراسات التربوية و النفسي 9 (Y (Y). 


$$
\begin{aligned}
& \text { عبدالسلام عبدالحميد عمران \& إياد علي مفتاح بالحاج } \\
& \text { المجلد (4) العدد (2) 2021م }
\end{aligned}
$$

\section{References:}

Amir, D., \& Sonderpandian, J. (2002). Complete Business Statistics. New York: McGraw - Hill .

Cronbach, L. (1970). Essentials of Psychological Testing. New York : Harper \& Row Publishers ,Inc.

Dustin TV Social Media Statistics, 2019 https://dustn.tv/social-media-statistics/

Edge, V.L, \& Shoukri, M.M (1996). Statistical Methods for Health Sciences. Boca Raton, Florida: CRC Press.

Kergcie, R.\& Morgan, D. W.,(1970), "Determining Sample Size for Research Activities", Educational and Psychological Measurement, vol. 30, pp. 607-610.

Munoz, C \& Towner T. (2009). "Opining Facebook: How to Use Facebook in the College Classroom". Conference Paper, Information Technology and Teacher Education conference. Charleston. South Carolina. USA.

Nunnally, J. C. (1978). Psychometric Theory. 2nd ed. New York : McGraw - Hill.

Rubin, A., \& Babbie, E. R. (2009). Essential Research Methods for Social Work. Belmont. CA: Wadsworth/Thomson Learning.

Sekaran , U . (2000) . Research Methods for Business . New York : John Wiley \& sons , Inc 